\title{
The French Reflexive and Reciprocal se
}

\author{
Marie Labelle \\ Université du Québec à Montréal
}

\begin{abstract}
It is argued that the reflexive clitic se does not operate in the lexicon in French reflexive and reciprocal constructions (excluding middles and anticausatives). The widely held approaches to reflexives, in which the reflexive clitic creates a one-place reflexive verb and/or absorbs a case feature on the verb, is both semantically inadequate and syntactically too local. The reflexive clitic appears with verbs and predicates that are independently semantically reflexive; French reflexive/reciprocal constructions are semantically transitive; and case absorption doesn't account for causative and applicative constructions. To account for the facts, it is proposed that $s e$ is a Voice head introducing in syntax the external argument of the verb, and stating that the referent of the object is determined on the basis of that of the subject.
\end{abstract}

\section{Introduction}

This paper studies the contribution of the reflexive clitic se in French productive reflexive and reciprocal clauses, that is, in constructions of types (1a) and (1b) below, where the superficial subject is, pretheoretically, interpreted as expressing two thematic roles, often but not exclusively those of Agent and Patient/Theme of the verb. 
(1) a. Reflexive : $\quad$ Luc se lave.

Luc SE wash-PRES-3s ${ }^{1}$

'Luc is washing (himself).'

b. Reciprocal: $\quad$ Luc et Pierre se regardent.

Luc and Pierre SE look-at-PRES-3P

'Luc and Pierre look at each other.'

The dominant approach to French reflexives is based on three assumptions: (1) se creates a reflexive verb; (2) the reflexive verb is unaccusative; (3) se reduces the accusative case-assigning property of the verb. These assumptions imply that se is a lexical operator on the verb. I argue against these three assumptions and show that in the constructions in (1) the role of se is not lexical.

There is a long tradition of treating reflexives as lexical operators that reduce the valency of the predicate they apply to (e.g. Quine, 1961; Grimshaw, 1982, 1990; Wehrli, 1986; Chierchia, 2004[1989]). Reinhart, for example, defines reflexivisation as an operation of reduction of

\footnotetext{
${ }^{1}$ I gloss the reflexive morpheme se as SE to indicate that the meaning is not necessarily reflexive. Other abbreviations used in this paper: $\mathrm{PRES}=$ present tense; $\mathrm{PP}=$ past participle; $\mathrm{FUT}=$ future; $\mathrm{PST}=$ past $3 \mathrm{~S}=$ third person singular; $3 \mathrm{P}=$ third person plural; $\mathrm{ACC}=$ accusative; $\mathrm{DAT}=$ dative; $\mathrm{NOM}=$ nominative; $\mathrm{NEG}=$ negation/negative particle; $\mathrm{DET}=$ determiner. By default, $\mathrm{AUX}$ indicates a tense auxiliary; to distinguish it from the passive auxiliary, I gloss AUX $\mathrm{XNS}_{\mathrm{TN}}$ and AUX $\mathrm{X}_{\mathrm{PASS}}$. Examples in other languages: $\mathrm{SM}=$ subject marker; $\mathrm{FV}=$ final vowel; $2=$ noun class; $\mathrm{REFL}=$ reflexive; $\mathrm{HAB}=$ habitual; RECIP=reciprocal.
} 
argument structure that applies to a two-place relation or predicate, identifies the two arguments and reduces the relation to a property (Reinhart, 1996; Reinhart and Siloni, 2004):
(2) a. wash $<\theta_{1}, \theta_{2}>$
b. $\quad$ Reduction: $\mathrm{R}$ (wash) $<\theta>$
c. $\quad(\mathrm{R}($ wash $)(\mathrm{x})) \longleftrightarrow(\mathrm{x}$ wash $\mathrm{x})$

This is equivalent to the SELF function of Grimshaw (1982). As reduction applies under identification of two $\theta$-roles, a two-place relation is required. Because it affects the argument structure of the verb, reflexivisation must be a lexical operation. The idea that French reflexives are the result of the lexical operation in (2) has recently been defended by Baauw and Delfitto (2005), according to whom there is a prohibition against valency reduction in syntax:

\section{(3) $\quad * \lambda y \lambda x(x R y) \rightarrow \lambda x(x R x)$}

For them, a two-place predicate (a relation) cannot be reduced to a one-place predicate (a property) by the computational system either in narrow syntax or in the course of the interpretation process. It follows that reflexive predicates must undergo (2) in the lexicon.

The reduction brought about by the reflexive operator in (2) results in an intransitive verb, and a question arises as to whether this verb is unergative or unaccusative. If the verb's argument is the external argument, the reflexive verb is unergative; if it is the internal argument, we have an unaccusative construction. A widespread approach since Marantz (1984) and Grimshaw 
(1990) is to treat reflexive/reciprocal constructions as unaccusative, on a par with the middle and the anticausative, where the surface subject is the logical object of the non-reflexive verb.
(4)
a. Middle :
Cette robe se lave
facilement.
this dress SE wash-PRES-3s easily
'This dress washes easily'
b. Anticausative: Le vase se brise.
the vase SE break-PRES-3S
'The vase is breaking'

The unaccusative approach to reflexives/reciprocals is appealing because it unifies the various uses of se, and it accounts for the selection of auxiliary être in the four se constructions. In this type of approach, se not only prevents the projection of the external argument in syntax, it also reduces the verb's accusative case assigning property, forcing the internal argument to raise to subject position in order to be case-marked (or to check case). Again, if se eliminates a Case feature on the lexical entry of the verb, it must be attached to the verb in the lexicon. This is also the case in Reinhart and Siloni's (2005) approach, in which the sole role of se is to lexically absorb a case feature on the verb, without making the verb unaccusative.

In a more syntactic implementation of the unaccusative approach, se is viewed as an anaphor generated in the specifier of $v$, the position of the external argument in a layered VP. It cliticises onto $v$, where it satisfies the Case feature of $v$. Subsequently, a caseless object raises to a position from where it binds the anaphor, and from where it can get Nominative Case (by raising to Spec,TP) (see, among others Pesetsky, 1995; McGinnis, 1997, 1999; Embick, 2004). Here again, se prevents the verb from assigning case to its object, which raises to subject position. 


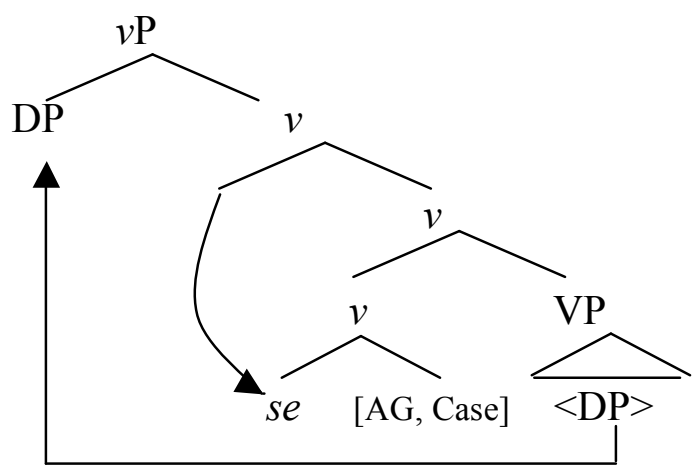

(from Embick, 2004)

There are many variants of the approaches sketched above (for a summary, see Alboiu et al., 2004). Most share the view that se operates at the lexical level in some manner, whether to absorb a thematic role and/or to reduce a verb's case feature. In the present paper, I argue that reflexive/reciprocal se does not operate in the lexicon. Its role is purely syntactic. Moreover, I will show that the above approaches are too local to account for reflexive and reciprocal se, and that the DP that surfaces in subject position is the external argument. I propose to analyse se as a Voice head that takes as its argument a VP with an unsaturated argument. When a DP is introduced in Spec,Voice, it is interpreted as the external argument and it is used to identify the unsaturated internal argument.

The paper is structured as follows. In section 2, I introduce the hypothesis that se is a Voice head. In sections 3 and 4, I show that se is not an operator of reflexivity and that it appears, apparently redundantly, in clauses containing a distinct reflexive morpheme. In sections 5 and 6 , I show that the case-aborption approach to se faces problems when complex constructions are examined. Then, I turn to other characteristics of reflexive and reciprocal clauses that show that the reflexivised verb has two distinct semantic arguments; hence se does not reduce the argument structure of the verb. In the last two sections, I briefly discuss the relation between se and nonreflexive clitics, and between reflexive/reciprocal clauses and middles/anticausatives. I focus on 
French, and I do not claim that the present approach extends to all other Romance languages without modification.

\section{Se as a Voice head}

In an seminal paper, Kratzer (1996) argued that external arguments are introduced in syntax by a separate functional head, a Voice head. In active sentences, the Voice head relates an event to its external argument.

(6) Active Voice: $\lambda \mathrm{x} \lambda \mathrm{e}[\operatorname{Agent}(\mathrm{e}, \mathrm{x})]$.

For concreteness, I use the label "Agent" throughout this paper to refer to the predicate's external argument. It should be recalled, however, that the exact thematic role of the external argument is determined jointly by the verb and its internal arguments (Marantz, 1984). I assume that the role of Voice is to introduce whatever external argument is required by the predicate. ${ }^{2}$

Kratzer furthermore proposes that there are two different realisations of Voice. Active Voice introduces an external argument, as shown above. Non-Active Voice does not introduce an external argument. With Active Voice, the external argument is realised in its specifier.

According to Kratzer, Voice combines with VP by a special mode of composition called Event Identification, defined as in (7).

(7) $\operatorname{ident}\left(\alpha_{\mathrm{ue}, \mathrm{ss}, t),} \beta_{\mathrm{s}, t)}\right) \equiv \mathrm{P} \lambda \mathrm{y}_{\mathrm{e}} \lambda \mathrm{e}_{\mathrm{s}}[\alpha(\mathrm{e}, \mathrm{y})$ and $\mathrm{P}(\mathrm{e})](\beta)$.

\footnotetext{
${ }^{2}$ Kratzer speculates that the repertoire of basic active voice heads is limited to two: one adding agents to action verbs and one adding holders (of a state) to stative verbs.
} 
The denotation of Active Voice is a function that takes an individual (e) and maps it to a function from events (s) to truth-values (t) $(<\mathrm{e},<\mathrm{s}, \mathrm{t}>>)$. As shown in (8a), Event Identification combines this denotation with the denotation of the VP, viewed as mapping events to truth values $(<\mathrm{s}, \mathrm{t}>)$. For example, the verb break in $(8 \mathrm{~b})$ forms with its complement a predicate without external argument. After combining with Active Voice, an Agent is added to the event denoted by the VP.

$$
\begin{aligned}
& \text { a. } \quad \operatorname{ident}\left(f_{<e, s \downarrow}, g_{<s, \downarrow}\right) \rightarrow h_{<e, s \triangleright}=\lambda x_{e} \lambda e_{s}[f(e, x) \wedge g(e)] \\
& \text { b. } \quad \operatorname{ident}\left(\lambda \mathrm{x}_{\mathrm{e}} \lambda \mathrm{e}_{\mathrm{s}}[\operatorname{Agent}(\mathrm{e}, \mathrm{x})], \lambda \mathrm{e}\left[\operatorname{break}\left(\text { the vase, e)]) } \rightarrow \lambda \mathrm{x}_{\mathrm{e}} \lambda \mathrm{e}_{\mathrm{s}}[\operatorname{break}(\text { the vase, } \mathrm{e}) \wedge \operatorname{Agent}(\mathrm{e}, \mathrm{x})]\right]\right.\right.
\end{aligned}
$$

It has long been recognised that reflexive clitic constructions, in particular in Romance, have something to do with licensing the external argument. In Spanish and Italian, se/si appears to bear the thematic role of the external argument in some impersonal constructions; other reflexive constructions share properties with passives and unaccusatives, where the external argument is not syntactically realised. This has been taken to indicate that reflexive clitics crosslinguistically prevent the realisation of the external argument, triggering raising of an internal argument to subject position (Marantz, 1984). Because the introduction of the external argument is the role of Voice within Kratzer's model, a number of authors have started to associate reflexive morphology with Voice. Some treat reflexives as Non-Active morphology (e.g. McGinnis, 1999). A distinct perspective is taken by Doron (2003), who posits a special Voice head called Middle Voice, $\mu$, to account for the Hebrew middle templates. In her analysis (p. 58), $\mu$ voids the licensing of Active Voice. As a result, the external argument is missing from the derivation. In addition, $\mu$ may optionally assign the thematic role of Agent to the verb's 
argument. In both cases only one argument is realised in syntax. This is illustrated in (9). Note that in (9a), there is both Event Identification and Argument Identification as defined in Higginbotham (1985), that is, identification of the argument of $\mu$ with that of the VP.

(9) a. y nidxaf 'x push-SIMPL-MID'

(Doron 2003, ex. 114)

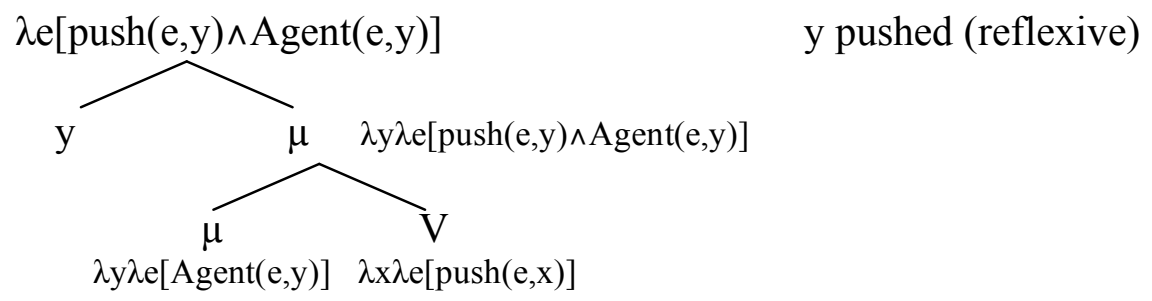

b. $\quad \mathrm{x}$ nišbar ' $\mathrm{x}$ break-SIMPL-MID'

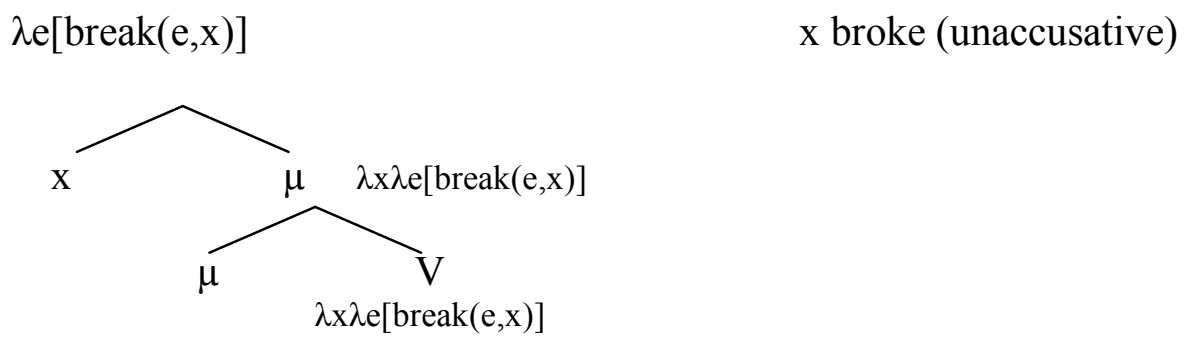

Yet another approach is taken by Bruening (2006) in his study of verbal reciprocals. Bruening analyses the verbal reciprocal as a special type of Voice head that combines, by Functional Application, with an open predicate, and states that the argument of Voice is both the Agent and the unsaturated internal argument of the VP:

(10)

$[[R e c i p V]]=\lambda f_{<e, s \triangleright} \cdot \lambda z|z| \geq 2 . \lambda e .\left[\forall x \in z . \exists y, q \in z .\left(x \neq y\right.\right.$ and $x \neq q$ and $\left(\exists e^{\prime}\left[f\left(e^{\prime}, y\right)\right.\right.$ and Agent(e', $\left.x\right)$ and e' $\leq e]$ and $\exists e "[f(e ", x)$ andAgent $(e ", q)$ ande" $\leq e]))]$ 
Here, I follow Bruening's type of approach. I propose to analyse the French reflexive/reciprocal se as a Voice head taking an open VP predicate (type $<$ e,st $>$ ) as its first argument and returning a predicate of the same type.

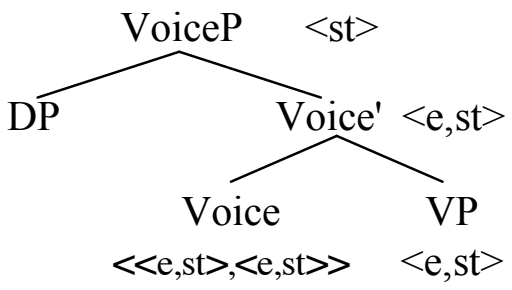

In French reflexive and reciprocal constructions, se shares with Active Voice the property of introducing the external argument in the clause. As a first approximation we may say that se has the denotation in (12) and that it combines with the VP as in (13):

$$
\text { se }=\lambda P \lambda x \lambda e[P(e, x) \wedge \operatorname{Agent}(e, x)]
$$

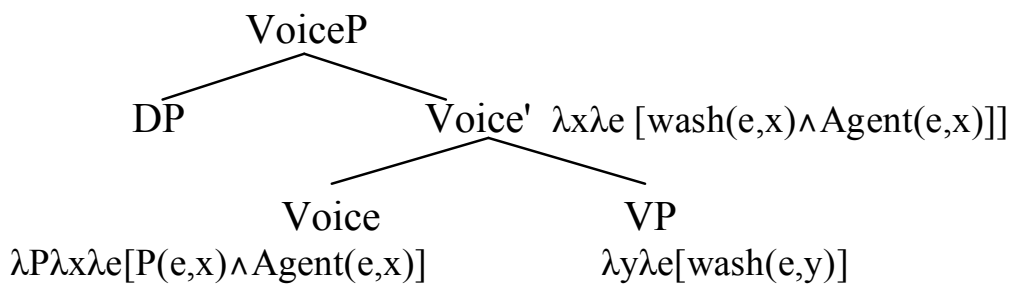

In (13), se combines by Functional Application with an open VP, that is, a VP containing an unsaturated internal argument, and it assigns the Agent role to the VP internal variable. The combination yields a one-place predicate where the VP internal variable has two thematic roles, a VP internal one and the role of Agent of the event. When a DP is introduced in Spec, Voice, it saturates both roles. Observe that the same result would be obtained by assuming that the 
reflexive head combines with VP by Event Identification and assigns the Agent role to the object (like $\mu$ in 9a):

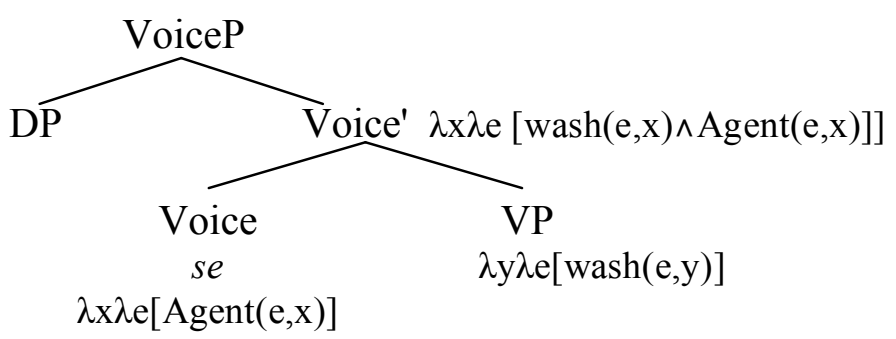

In (14) the only difference between se and Active Voice lies not in the denotation of se but in its mode of composition with the VP: a special mode of composition must be defined for se that allows it to combine with an open VP and that identifies the arguments of se and of the VP. I choose to encode this in the lexical entry of se, as in (12), and to rely on Functional Application instead of on a combination of Event Identification and Argument Identification. We will revise (12) in section 7.

I assume that (12) also holds for reciprocals, the difference being that, in reciprocals, the subject is a plural argument. This captures the fundamental role of reflexive/reciprocal se: that of introducing an external argument and of ensuring that the DP in Spec, Voice is interpreted as being both the external argument and the missing internal argument. I do not discuss here the various readings of reciprocal clauses. ${ }^{3}$

I am concerned here, not with the technical details of the syntactic derivation, but with the specific contribution of se. However, for concreteness, I sketch here the syntactic assumptions underlying the present work. I assume that se is generated as the head of a Voice Phrase

${ }^{3}$ See Fiengo and Lasnik (1973) and Dalrymple et al. (1998). See also Bruening (2006) for a discussion of verbal reciprocals. 
dominating VP, and that it moves to its surface position (under $\mathrm{T}$ in tensed clauses). I take Voice to be a syntactic functional head.

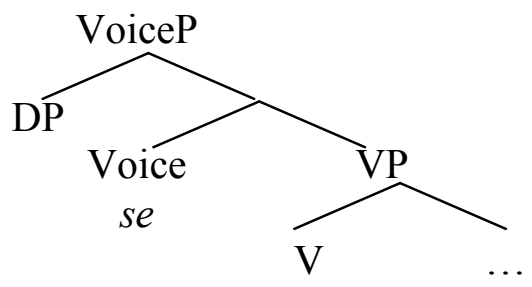

The DP in Spec,Voice is the external argument, which moves to Spec,TP in SVO clauses. The lexical verb independently moves to $\mathrm{T}$ in simple tenses and remains in a lower position in complex tenses. This accounts for the possible separation of se and the lexical verb in syntax, illustrated in (16). Assuming that tous signals the initial position of the external argument in Spec,Voice - it is the remnant of tous les enfants from which les enfants has moved to Spec,TP (Sportiche 1988) - the syntactic derivation of (16a) is as in (16b). ${ }^{4}$ There is no empty category in syntax in the position of the reflexivised object.

(16) a. Les enfants se sont tous soigneusement lavés. the children SE AUX-3P all carefully wash-PP 'The children all washed (themselves) carefully.'

b. [TP Les enfants $\mathbf{s}_{\mathrm{i}} \mathbf{s e}_{\mathbf{k}}$ sont [VoiceP tous les enfants $\mathrm{s}_{\mathrm{i}} \mathrm{se}_{\mathrm{k}}\left[\mathrm{VP}\right.$ soigneusement lavés $\left.\left.\left.{ }_{{ }_{\theta}>}\right]\right]\right]$

4 In (16b), I abstract away from the possibility that past participles move out of the VP to a functional head (Kayne, 1989). Nothing of what I have to say hinges on this. Also, nothing in the present analysis of se requires VoiceP to immediately dominate VP. Other heads might intervene. 
Se is only compatible with VPs where the missing object would bear accusative or dative case. It does not appear in a reflexive clause if the internal complement coreferential with the subject would bear a case different from accusative or dative. For example the complements in (17) are cliticisable, but not by an accusative or dative pronoun (en is genitive/partitive and $y$ is locative). If these sentences are reflexivised, a full pronoun must surface in object position, and se is excluded (18). ${ }^{5}$

(17) a. Luc a peur de son voisin. $\rightarrow$ Luc en a peur.

Luc has fear of his neighbour. Luc of-him has fear

b. Luc pense à sa famille $\quad \rightarrow$ Luc y pense.

Luc thinks of his family (lit. 'to') Luc of-it thinks

(18) a. Luc a peur de lui-même. $\quad \rightarrow$ *Luc s' a peur.

Luc has fear of himself. Luc of-himself has fear

b. Luc pense à lui-même $\quad \rightarrow$ *Luc se $\quad$ pense.

Luc thinks of himself (lit. 'to') Luc of-himself thinks

I assume that this case specificity of $s e$ follows from the fact that $s e$ bears an accusative/dative case feature that needs to be checked, and take the relation between se and the internal case

\footnotetext{
${ }^{5}$ See Zribi-Hertz (2003) and Rooryck and Van den Wyngaerd (1999b) for a discussion of sentences like those on the left-hand side of (18).
} 
feature to be an agreement relation. Using minimalist terminology, we may say that when se is introduced in the derivation, it probes the structure for an appropriate case. ${ }^{6}$

\section{Se is not a reflexive operator}

Let us start by considering the hypothesis that se performs a reflexive operation on the verb, like the one illustrated in (2). At first sight, this idea works fine. In (19) se reflexivises the verb, and in (20) it yields a reciprocal meaning. The morpheme se is required to get the reflexive/reciprocal meaning; (19) without se is not reflexive, and (21) is ungrammatical or incomplete.

(19) Luc se parle.

Luc SE talk-PRES-3S

'Luc talks to himself'

(20) Les enfants s' aiment.

the children SE love-PRES-3P

'the children love each other'

(21) *Les enfants aiment.

the children love-PRES-3P

${ }^{6}$ This is similar to what Chomsky suggests in the following quotation on subject-oriented reflexives: "In a structure of the form $\{\mathrm{SPEC},\{\mathrm{H}, \ldots \mathrm{R} \ldots .\}$.$\} [ML: Where \mathrm{H}$ is a head and $\mathrm{R}$ the reflexive object], with $\mathrm{R}$ c-commanded and bound by SPEC, R could be taken to be the goal probed by $\mathrm{H}$, and thus only indirectly bound by SPEC; hence a case of Agree, not c-command.". (Chomsky 2005: 3) 
A simple analysis of these facts is to say that se attaches to a dyadic verb to yield a monadic verb where the single argument of the verb saturates the two thematic roles, as in the b examples below.

(22) a. parler 'talk' $=\lambda x \lambda y \lambda e[$ talk-to(e,x) and Agent $(e, y)]$

b. $\quad$ se parler $=\lambda x \lambda e[\operatorname{talk-to}(e, x)$ and $\operatorname{Agent}(e, x)]$

(23) a. aimer 'love' $=\lambda x \lambda y \lambda e[\operatorname{love}(e, x)$ and $\operatorname{Agent}(e, y)]$

b. $\quad$ s'aimer ${ }_{\text {recip }}=\lambda X \lambda \mathrm{e}[\operatorname{love}(\mathrm{e}, \mathrm{X})$ and $\operatorname{Agent}(\mathrm{e}, \mathrm{X})]$, where $|\mathrm{X}| \geq 2$. $^{7}$

But a problem arises when we consider lexically reflexive verbs like autoanalyser 'selfanalyse' (also autofinancer 'self-finance', autoproclamer 'self-proclaim', autocélébrer 'selfcelebrate', autodétruire 'self-destruct'...) and lexically reciprocal verbs like entreregarder 'look at one another' (also entraccuser 'accuse one another', entraider 'help one another', entredéchirer 'tear one another to pieces', entredétruire 'destroy one another',...). Here, the prefix conveys the reflexive meaning in the case of auto- and the reciprocal meaning in the case of entre-. Despite being lexically reflexive/reciprocal, these verbs require the reflexive clitic, as shown by the ungrammaticality of the b examples below. ${ }^{8}$

\footnotetext{
${ }^{7}$ As mentioned above, I limit myself here to assuming that the reciprocal interpretation requires a set of cardinality equal to or higher than 2 .

${ }^{8}$ See Embick (1997, 2004:144-146) for a similar observation regarding afto- prefixation and nonactive morphology in Greek.
} 
(24) a. Jean s' autoanalyse.

Jean SE self-analyze-PRES-3S

b. *Jean autoanalyse.

(25) a. Les participants s' entreregardèrent.

the participants SE entre-look-at-PST-3P

'The participants looked at one another.'

b. *Les participants entreregardèrent.

Some attested examples of auto- and entre-prefixed verbs are listed in (26)-(27). It must be noted that the process of auto- and entre-prefixation is productive, as can be seen in (26d) and (27c,d). This means that every time a speaker creates a new verb by adding auto- to an existing verb, the reflexive morpheme appears on the derived verb. Similarly with the prefix entre- creating reciprocal predicates. ${ }^{9}$

${ }^{9}$ A reviewer asks about the difference between (i) and (ii).

(i) Marie a entrecroisé les fils bleus et verts.

Marie AUX intertwine-PP the threads blue and green

'Marie has intertwined the blue and green threads'

(ii) Les fils bleus et verts se sont entrecroisés.

The threads blue and green SE AUX intertwine-PP (lit.: crossed each other)

'the blue and green threads intertwined'

In (i) there is no coindexation between the external argument and an internal argument, and se doesn't appear. Entre- operates at the level of the predicate embedded under CAUSE: [x CAUSES [y and $\mathrm{z}$ to cross each other]]. Se appears in (iii), where the reciprocity involves an agentive plural 
(26) a. vous aviez encouragé Mobutu à s' autoproclamer maréchal you AUX-PST encourage-PP Mobutu to SE self-proclaim Marechal 'you had encouraged Mobutu to proclaim himself Marechal' (www.congonline.com)

b. je peux m' autosuggérer plein de trucs I can SE-1S self-suggest many of things 'I can suggest a lot of things to myself' (forum.hardware.fr)

c. un placement qui $\mathbf{s}^{\prime}$ autofinance pour la retraite an investment that SE self-finance-PRES-3S for the retirement 'an investment that finances itself for one's retirement' (achat-vente-appartement. vivastreet.fr)

subject and the implicit internal argument (there is also a non-agentive reading of (iii) similar to (ii)).

(iii) Les patineurs s' entrecroisent sur la glace. the skaters SE criss-cross-PP on the ice. (lit.: cross each other) In (ii) s'entrecroiser is ambiguous between the equivalent of (iii) and the anticausative of (i) (with a reciprocal interpretation); in the latter case, the superficial subject is a deep object and se is the anticausative morpheme. The crucial point for us is that when entre- introduces reciprocity between the plural set denoted by the external argument (the Agent) and the same set bearing an internal role, se is required even though the reciprocal interpretation is given by the prefix. 


\section{d. Il s' est autocréé cette carapace.}

He SE AUX self-create-PP this shell.

'he created this shell around himself'

(TV report on Giscard d'Estaing)

(27)

a. Les guérilleros s' entretuent pour la "route de la cocaïne".

The guerilleros SEkill_each_other-PRES-3P for the "road of the cocaine".

'The guerilleros kill each other for the cocaine road.'

(Le Monde, February 20, 2007)

b. Des musulmans s' entredéchirent.

(some) muslims SE tear_one_another_to_pieces-PRES-3P

'Muslims tear each other to pieces'

(www.soirinfo.com/article.php3?id_article $=2519$ )

c. elle n' est plus lue que par les poètes qui $\mathbf{s}^{\prime}$ entrelisent

it-FEM NEG is now read only by the poets who SE read_each_other-PRES-3P, comme s' entredévorent certains insectes?

like SE devour_each_other-PRES-3P certain insects

'It is only read by poets who read each other like certain insects devour each other.'

(www.quebecoislibre.org)

d. les membres de 1' alliance présidentielle qui ne ratent décidément the members of the alliance presidential who NEG miss really aucune opportunité pour s' entredécocher des fléchettes empoisonnées.... any opportunity to SE send_each_other DET darts poisoned 'the members of the presidential alliance who really never miss an opportunity to send each other poisoned darts' 
(www.liberte-algerie.com, March 2, 2007)

This raises the following question: Why does se appear with SELF-derived verbs? Assume that the prefixes auto- and entre- derive monadic verbs from dyadic verbs. By prefixing a twoargument verb with auto- or entre- we obtain a different verb selecting only one argument. Schematically:

$$
\text { analyser }=\lambda x \lambda y \lambda e[\text { analyse }(e, x) \text { and } \operatorname{Agent}(e, y)]
$$

$\rightarrow$ autoanalyser $=\lambda x \lambda e[$ analyse $(e, x)$ and $\operatorname{Agent}(e, x)]$

$$
\begin{aligned}
& \text { regarder }=\lambda x \lambda y \lambda e[\text { look-at }(e, x) \text { and } \operatorname{Agent}(e, y)] \\
& \rightarrow \text { entreregarder }=\lambda X \lambda \mathrm{e}[\text { look-at }(e, X) \text { and } \operatorname{Agent}(e, X)], \text { where }|X| \geq 2
\end{aligned}
$$

If se operates on dyadic lexical entries, as defined in (2), it should not be able to attach to the derived verbs. The semantics of these verbs corresponds to the result of the reduction operation in $(2 \mathrm{c})$. It is clear that the role of $s e$ is not to make the verbs semantically reflexive or reciprocal, because the prefixes serve this role in the examples given. From a semantic point of view, se appears to be redundant. The argument extends to the semantically reflexive verb se suicider 'commit suicide', where sui means 'self' and cide 'kill'; if se is a reflexiviser, why does it attach to suicider $?^{10}$ With these verbs is doubtful that se is added to the verb in the lexicon:

\footnotetext{
${ }^{10} \mathrm{We}$ are not trying to account here for all the so-called intrinsic reflexives of traditional French grammar. The term intrinsic reflexive is a cover term for a heterogeneous set of verbs that exist only with the reflexive morpheme. In some cases the process leading to the creation of the se+V collocation is not productive or no longer productive; the collocation often has an idiosyncratic
} 
there is no reflexive operation to perform at that level. We have to conclude that se must be present to satisfy some other well-formedness condition.

The obligatoriness of $s e$ with SELF-derived verbs follows if se classifies, or marks, the predicate as reflexive at the level of the Voice head. Reinhart and Reuland (1993) introduce the concept of reflexive-marking and use it to define Conditions A and B below:

(30) Condition A: A reflexive-marked (syntactic) predicate is reflexive.

Condition B: A reflexive (semantic) predicate is reflexive-marked.

Condition A states that if a predicate is marked as reflexive in the syntax, it is interpreted as semantically reflexive. ${ }^{11}$ Condition $\mathrm{B}$ states that if a predicate is semantically reflexive, it must be marked as reflexive. Putting aside the way these authors define reflexive-marking (see note 12), we may apply these conditions to the facts we have been discussing in the following way. The reflexive/reciprocal interpretation in (19) and (20) results from Condition A: because parle and aiment are marked as reflexive by se, they are interpreted as reflexive/reciprocal (see Dobrovie-

interpretation (se tromper 'err'), and its subject is often not an external argument (se souvenir 'remember'). Where they do not lend themselves to a synchronic analysis, these collocations are best treated as idioms. What we claim in the text is that the obligatoriness of the reflexive morpheme finds a principled explanation in the case of SELF-derived verbs and of suicider, which have a clear reflexive or reciprocal interpretation, and that these verbs should not be treated as lexicalised collocations. Grevisse and Goose $(2007, \S 779$ R4) treat these verbs as distinct from intrinsic reflexives for exactly the same reason.

11 Here, we need to abstract away from middle and unaccusative interpretations. 
Sorin, 1998:402, for a similar proposal). Condition B is at play in (24) and (25): because autoanalyse and entreregardent are semantically reflexive/reciprocal, the predicate must be marked as reflexive by se.

Conditions $\mathrm{A}$ and $\mathrm{B}$ follow if we assume that se is a Voice head that :

1- combines with an open VP;

2- introduces an external argument;

3- identifies the external argument with the free variable within the VP.

This is illustrated in (31). The verb parle 'speak' is not semantically reflexive. The VP contains a variable for the Goal object associated with the verb. When se is added to the derivation, it adds the Agent role to the object variable. When $L u c$ is introduced in Spec,Voice, it saturates the Agent of the speaking event, and the Goal of that event. (I assume that dative objects are DPs, and that $\grave{a}$ is a case-marker rather than a preposition (Kayne, 1975)).

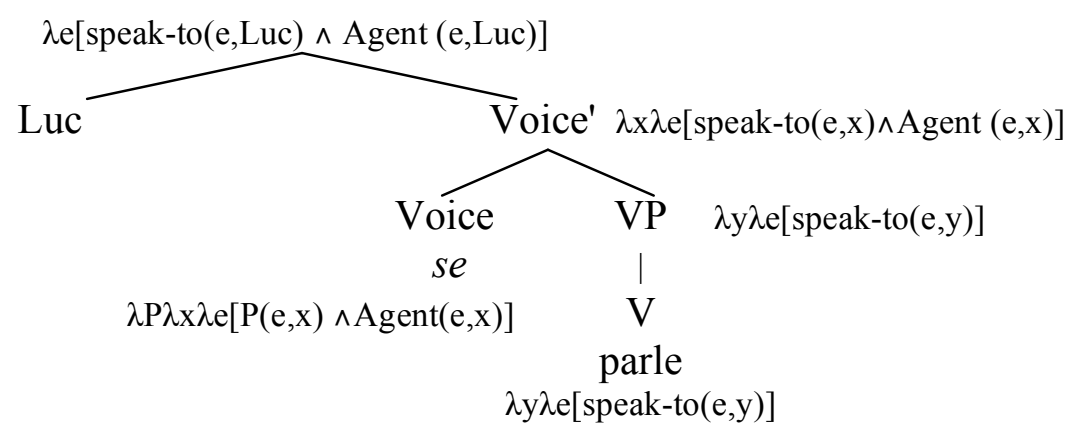

Let us now turn to the verb autoanalyse in (24). When an auto- prefixed verb is introduced in syntax, it selects an Agent coreferential with the object. Suppose we encode this selectional restriction explicitly as in (32), where the prefix auto introduces the Agent in the verb's lexical 
entry. The verb is then treated as an exception to Kratzer's generalisation that external arguments do not appear in the lexical representation of verbs. In (32), se is redundant. It does not add information to what the verb lexically contains. The Agent contributed by se is non-distinct from the Agent role already present in the lexical entry of the verb. When Jean is introduced in Spec,Voice, it is interpreted as being both the Agent and the Theme of the event, as required by the meaning of the verb.

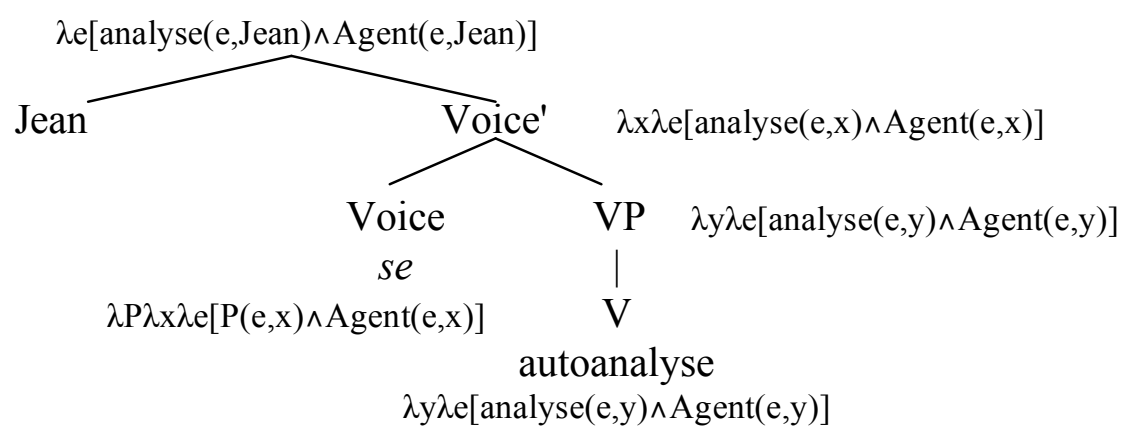

$\mathrm{Se}$ is obligatory with this verb because the meaning of the verb requires that the Agent be the same entity as the Theme. Without se, Active Voice would introduce a distinct variable for the subject, counter-indexing will be assumed, and we would end up with two distinct Agents, violating the principle that a thematic role can only be assigned once. The sentence would be semantically incoherent.

Thus, if the verb is not lexically reflexive, se introduces a reflexive interpretation; this is the essence of Condition A. If the verb is lexically reflexive, se is nevertheless required to ensure the coherence of the interpretation; this is the essence of Condition B. ${ }^{12}$ In this sense, we may say

${ }^{12}$ The present analysis is radically different from Reinhart and Reuland's. For these authors a predicate is reflexive-marked if and only if (i) it is lexically reflexive or (ii) one of its arguments is a SELF anaphor, where a SELF anaphor is a morphologically complex anaphor like himself. For 
that $s e$ is a grammatical means of classifying a predicate as reflexive: it classifies the predicate as reflexive by marking it as being one in which two arguments, the external argument and an internal argument are coreferential.

To summarise, the presence of the reflexive clitic with verbs like autoanalyser or entreregarder indicates that the role of se is not to create a semantically reflexive/reciprocal verb. It was suggested that its role is to mark the predicate as reflexive in syntax, and that it fulfills this role by introducing, at the level of the Voice head, an external argument specified as being coreferential with an unsaturated internal argument.

\title{
4 Se...lui-même
}

In (33) and (34), the complement position is filled by a full (i.e. non-clitic) anaphoric pronoun, reflexive (lui-même) or reciprocal (l'un l'autre).

\author{
(33) a. Le ministre se copie lui-même. (www. liberation.fr) \\ the deputy SE imitate-PRES-3s himself \\ 'the deputy imitates himself.'
}

\footnotetext{
them, SE anaphors are intrinsically unable to reflexive-mark a predicate. These authors never explicitly state that French se is a SE anaphor, but their analysis implies it, because it is a morphologically simple anaphor similar to Italian $s i$ in the relevant respects. In addition, for these authors, a lexically reflexive predicate is reflexive-marked. Autoanalyser, entreregarder, and suicider are lexically reflexive. In Reinhart and Reuland's system, these verbs should not trigger the reflexive-marking of the predicate.
} 
b. Les voisins se détestent les uns les autres.

the neighbours SE detest-PRES-3P the ones the others

'The neighbours detest one another.'

(34) a. Le ministre se parle à lui-même. (www. liberation.fr)

the deputy SE talk-PRES-3s to himself

'The deputy talks to himself.'

b. Quand le député-Maire se fait des cadeaux à lui-même.

when the deputy-mayor SE make-PRES-3S DET gifts to himself

'When the deputy-mayor makes gifts to himself...'

c. Les jeunes se parlent les uns aux autres.

The young_people SE speak-PRES-3P the ones to_the others

'The young people speak to each other.'

d. Vadius et Trissotin s' adressent l'un à l'autre des louanges

Vadius and Trissotin SE address-PRES-3P the one to the other DET praises

ridicules

ridiculous

'Vadius and Trissotin address each other ridiculous praises.'

(www.abnihilo.com/a/ar.htm)

Let us make a parenthesis to mention that, like himself in English and equivalent pronouns in other languages, lui-même has a variety of uses. Lui-même in the above sentences is not to be confused with the use exemplified in (35) where the pronoun 1) occupies a non-argumental position; 2) is an 'actor-oriented intensifier' that explicitly emphasises the subject and contrasts it 
with possible alternative actors (Rooryck and Vanden Wyngaerd, 1999a; Gast and Siemund, 2006). ${ }^{13}$

(35) Renaud diffuse ses MP3 lui-même sans l' avis de Virgin!

Renaud broadcasts his MP3 himself without the consent of Virgin (http://www.ratiatum.com/journal.php?id=2556)

By contrast, in (33a)-(34a,b), lui-même 1) occupies an argumental position and 2) introduces object contrast. Semantically, the reflexive pronoun lui-même in these examples, is not actor-oriented, but it serves to contrast the object with possible alternatives. In (33a), the deputy would be expected to copy other people; in (34a), the deputy would be expected to talk to other people. L'un l'autre in (33b) and (34c-d) forces the reciprocal interpretation of the clause. The fact that lui-même and l'un l'autre occupy an argument position is clear in (34), where the pronouns are case-marked by $\grave{a}$.

Not only does se happily coexist with lui-même/l'un l'autre in object position, it is obligatory in that context. In French, it is impossible to omit se in the presence of lui-même: ${ }^{14}$

\footnotetext{
${ }^{13}$ For a discussion of lui-même, see Zribi-Hertz (1990, 1995 and 2003)

${ }^{14}$ French differs from Italian. In Italian, there is complementary distribution of the clitic with the full pronoun. Alboiu et al. (2004) use this complementary distribution as an argument in favour of movement of the internal DP to subject position. This argument does not carry over to French.

(i) a. Gianni difende sé/ se stesso. [It] (Alboiu et al., 2004, ex. 11)

Gianni defends SE (SELF.M-emphatic)
} 
(36) a. *Le ministre copie lui-même.

b. *Les voisins détestent les uns les autres.

(37) a. *Le ministre parle à lui-même. ${ }^{15}$

b. *Les voisins envoient des injures les uns aux autres.

The obligatoriness of se with lui-même in French is unexpected if se is thought to reflexivise a predicate. The object position is filled by a reflexive or reciprocal pronoun, making the predicate semantically reflexive/reciprocal. Just as was the case with auto- and entre-derived verbs, se appears to be redundant. Again, if lui-même/l'un l'autre are not accusative or dative (and if the predicate is not otherwise reflexive), se is not present:

(38) a. Pierre votera pour lui-même.

b. *Pierre se votera pour lui-même

Pierre (SE) vote-FUT-3s for himself

'Pierre will vote for himself.'

b. Gianni si difende.

Gianni SE defend

c. *Gianni si difende sé/ se stesso.

Gianni SE defends SE (SELF.M-emphatic)

'Gianni defends himself.'

15 This example might be acceptable in a context where himself is interpreted as a pronoun that happens to refer back to the subject ministre. 
c. Les enfants voteront les uns pour les autres.

d. *Les enfants se voteront les uns pour les autres.

The children (SE) vote-FUT-3P the ones for the others

'The children will vote for one another.'

We must conclude that the role of $s e$ is not to make the predicate reflexive. Its presence finds an explanation if se reflexive-marks the predicate and if French requires the presence of se to encode the coreference between the subject and an accusative or dative object.

I assume that the anaphor does not saturate the internal argument, otherwise the resulting VP would be of type $<\mathrm{s}, \mathrm{t}>$, incapable of associating with se. It could be that the anaphor is a predicate modifier that doesn't saturate the predicate (cf. Chung and Ladusaw's (2003) Restrict mode of composition). Alternatively, the anaphor translates as a formula containing a variable, as in Déchaine and Wiltschko's (2004) analysis of reciprocals:

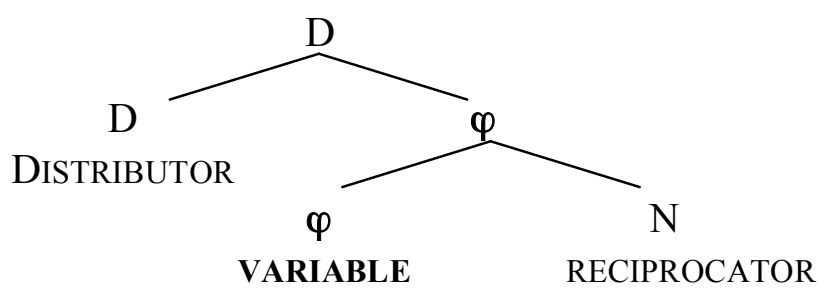

According to (39), the structure of l'un l'autre is [dist l'un [e [recip l'autre]]]. The variable e is then bound by se and coindexed with the plural subject; l'un ('the one') and l'autre ('the other') refer to members of the set denoted by the subject (see also Milner, 1984). ${ }^{16}$

\footnotetext{
${ }^{16}$ The variable here could be a trace of movement. See (50) below for an example of this type of derivation.
} 
Finally, observe that both lui-même and l'un l'autre occupy the object position and are case-marked. Hence, se does not prevent the verb from assigning case to its object. In other words, the unaccusative approach to se does not account for these sentences.

We will come back to (33)-(34) in section 7.2, when we discuss the contribution of luimême in the clause.

\section{Se, case-absorption, and causatives}

In section 3, it was shown that se is not a lexical operator of reflexivity, because it co-occurs with reflexive verbs. It will now be shown that se is also not a lexical case-absorber on the verb.

Reinhart and Siloni (2005) claim that languages are parameterised as being "syntax" languages or "lexicon" languages according to the level at which reflexivity is derived. They argue that French is a "syntax" language. One of Reinhart and Siloni's arguments is that se may appear on a head without affecting the argument structure of that head, something that is not possible in "lexicon" languages like Hebrew. Consider (40a) (Reinhart and Siloni, 2005: 394, ex. (5)). In this example, the matrix verb considère 'consider' does not take a DP as its internal argument; Pierre receives its thematic role from the adjective intelligent. Because the object is not an argument of the verb, it cannot be affected by a lexical operation on the argument structure of the verb. However, we see in (40b) that the reflexive morpheme se appears on the verb. Hence, according to the authors, reflexivity must be derived in syntax, a conclusion to which we subscribe.

(40) a. Luc considère Pierre intelligent.

Luc consider-PRES-3S Pierre intelligent

'Luc considers Pierre intelligent' 

b. Luc se considère intelligent.
Luc SE consider-PRES-3S intelligent
'Luc considers himself intelligent.'

Observe that the same holds for reciprocals; this tells us that French reciprocals are also derived in syntax (on reciprocals, see Siloni, to appear):

\author{
(41) Elles \\ se jugent \\ (respectivement) incompétentes. \\ They-FEM-PL SE consider-PRES-3P(respectively) incompetent-FEM-PL \\ 'They consider each other incompetent.' \\ Luc et Eva se croient mariés (l'un à l'autre). \\ Luc and Eva SE think-PRES-3P married (the one to the other) \\ 'Luc and Eva think that they are married to one another.'
}

Reinhart and Siloni develop an analysis where the role of se is solely to remove a case feature on the verb. The reflexive clitic is part of the verb's morphology, but it is not an argument, and it does not affect the number of thematic roles associated with the verb. When a reflexive verb is introduced in syntax, an internal thematic role is not mapped onto its canonical position, because it lacks case. It is retained on the verbal projection as long as the cycle is not completed. When the external argument is introduced in the derivation (at the IP level for them), all unassigned thematic roles must be assigned, otherwise the derivation crashes. At this point, an operation named Bundling takes place. This operation, defined as in (43) (their ex. 24, p. 400), assigns a bundle of the two thematic roles to a unique argument. The operation is constrained to operate on an external thematic role. 
(43)

Reflexivization Bundling

$\left[\theta_{\mathrm{i}}\right]\left[\theta_{\mathrm{j}}\right] \rightarrow\left[\theta_{\mathrm{i}}-\theta_{\mathrm{j}}\right]$, where $\theta_{\mathrm{i}}$ is an external $\theta$-role.

ex.: wash $<\theta_{1}, \theta_{2}>\rightarrow$ wash $<\theta_{1}-\theta_{2}>$

Bundling is interpreted as a distributive conjunction of theta roles: (44a) is interpreted as (44b).

It is argued that Bundling applies in syntax in French (whereas it applies in the lexicon in Hebrew).

The derivation proposed by these authors is illustrated in (45). At the embedded IP level, the verb laver 'wash' is associated with two thematic roles, Agent $\theta_{\mathrm{i}}$, and Theme $\theta_{\mathrm{g}}$. The Theme role is assigned to Marie, but the Agent role is not assigned and stays on the verb; this is represented as $<\theta_{\mathrm{i}}>$ in (45b). The main verb se-voir is then added to the derivation (45c). In the absence of se, the subject of the embedded clause would need to be projected in order for voir to check its accusative case feature. Se-voir has no accusative case to check, and this enables the derivation to continue. At the top IP level (45d), a subject, $L u c$, is introduced. Because this is the end of the cycle, all unassigned thematic roles must be assigned. Bundling takes place at that level, and $L u c$ receives a bundle composed of the two unassigned thematic roles, $\theta_{\mathrm{i}}$, Agent of laver, and $\theta_{\mathrm{k}}$, Agent of voir. As a result, (45d) is interpreted as in (46). 
(45) a. Luc se voit [laver Marie]. (Reinhart and Siloni, 2005 p. 405, ex. 34)

Luc SE sees wash Marie

'Luc sees himself wash Marie.'

b. Embedded IP: [IP[laver $<_{\theta i}>$ Marie $\left.\left._{\theta g}\right]\right]$

c. Next VP: $\left[\right.$ VP se voit $\left.{ }_{\theta \mathrm{\theta}>}>\left[\mathrm{IP}\left[\operatorname{laver}_{{ }_{\theta} i>}>\text { Marie }_{\theta \mathrm{g}}\right]\right]_{\theta \mathrm{\theta}}\right]$

d. Top IP: [IP Luc $\left.\left.\operatorname{luk}_{\theta \mathrm{i}}\left[\mathrm{VP} \text { se voit [IP[laver Marie }{ }_{\theta \mathrm{g}}\right]_{\theta \mathrm{f}}\right]\right]$

(46) $\exists \mathrm{e}_{1} \exists \mathrm{e}_{2}\left[\operatorname{see}\left(\mathrm{e}_{1}\right)\right.$ and wash $\left(\mathrm{e}_{2}\right)$ and $\operatorname{Agent}\left(\mathrm{e}_{1}, \operatorname{Luc}\right)$ and Theme $\left(\mathrm{e}_{1}, \mathrm{e}_{2}\right)$ and $\operatorname{Agent}\left(\mathrm{e}_{2}\right.$, Luc $)$ andTheme(e $e_{2}$, Marie)] (Reinhart and Siloni, 2005 p. 406, ex. 36)

Observe that the derivation is not unaccusative: the verb's superficial subject is introduced in Spec,IP.

This approach, correctly in my opinion, derives reflexivity in syntax. However, it is too local. It accounts for reflexivisation of the subject of an ECM predicate, case-marked by the verb on which se appears, but it fails to account for other constructions where the case of the object is a property of a head distinct from the head on which se cliticises.

Consider the causative constructions illustrated in (47) and (48). Causative constructions are a clear case for reflexivisation in syntax. In these constructions, it is evident that se has the 'displacement' property: it is found in a position different from the one in which the corresponding thematic role is interpreted (indicated with $<\theta>$ below). 
(47) Les citoyens se sont tous très souvent laissé bêtement [vp berner $<\theta>$ The citizens SEAUX-3P all very often let-PP stupidly deceive par le maire].

by the mayor

'The citizens very often let themselves all stupidly be deceived by the mayor.'

$$
\begin{aligned}
& \text { Luc se fait rarement [vp faire un complet neuf }<\theta>\text { par M. Dupont]. } \\
& \text { Luc SE CAUSE-PRES-3s rarely make a suit new _ by Mr. Dupont. }
\end{aligned}
$$

'Luc rarely has a new suit made for him by Mr. Dupont.'

Notice that none of the verbs of these sentences is semantically reflexive: there is no coreference between their thematic subject and their thematic object. Once again, we have to reject a lexical approach to reflexivisation. Crucially, however, the case-absorption approach proposed by Reinhart and Siloni does not work here. The missing accusative complement in (47) or dative complement in (48) is associated with the lower verb, but se appears on the higher verb, or on the auxiliary of the higher verb. The only way to preserve a lexical case-absorption analysis in this case would be to assume some type of complex predicate formation (Guasti, 1996; Zubizarreta, 1987, Baauw and Delfitto, 2005) in the lexicon, allowing se to operate on a case feature associated with the lower verb. The fact that the relevant verbs are morphologically and syntactically independent — they are separated by adverbs — raises doubts as to the correctness of these solutions (Miller, 1992:236; Folli and Harley, 2004). Moreover, whenever se is on the higher verb, the construction is of the faire-par type, a construction where the internal arguments of the embedded VP are standardly analysed as being case-marked internally to that VP (Burzio, 
1986; Guasti, 1996; Folli and Harley, 2004). ${ }^{17}$ If se is to absorb case, it appears on the wrong verb. It is of course unnecessary to rely on this type of solution if the reflexive morpheme is not a lexical operator.

In the present perspective, se does not remove the verb's case feature in the lexicon; it agrees at a distance with a case feature. The semantic derivation proceeds as follows: the variable corresponding to the internal argument of the lower verb berner remains in the derivation until se is introduced. When se is introduced, it assigns this variable an Agent role. The constituent les citoyens in Spec,Voice saturates both occurrences of the variable. This is illustrated in (49) for sentence (47) (ignoring adverbs and tense). ${ }^{18}$

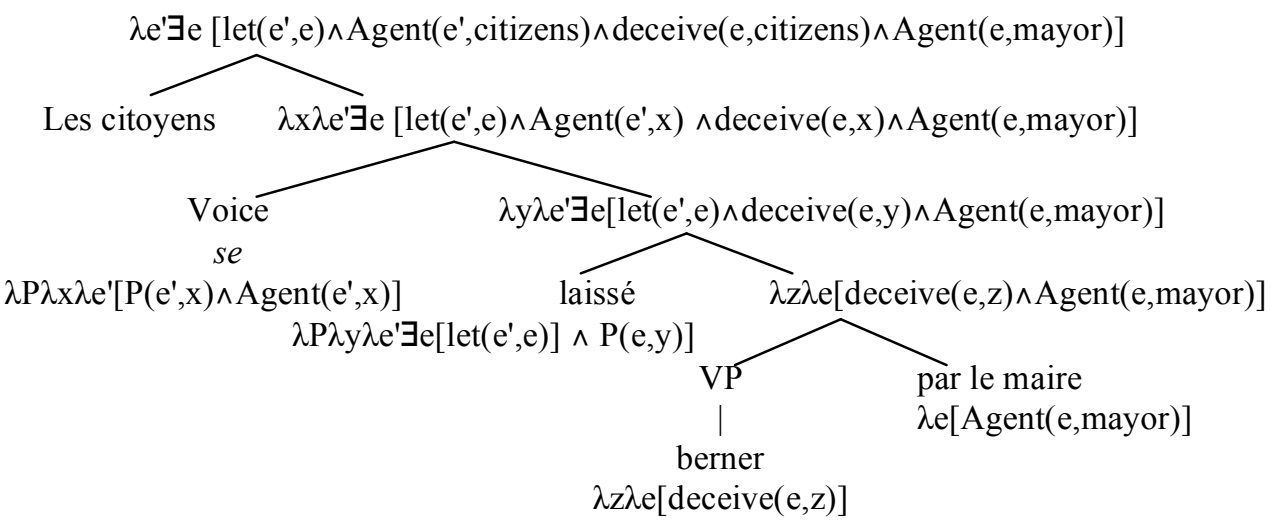

In (49) the translation of the causative verb allows it to combine with VP's, i.e. with relations between individuals and events. This is not specific to reflexives; it must be postulated to account for the placement on the higher verb of non-reflexive object clitics associated with the

${ }^{17}$ On faire-par see footnote 26.

${ }^{18}$ Here I oversimplify in places irrelevant to the analysis. In particular, I gloss over the problem of defining the exact thematic role of the subject of laisser, identifying it as a type of 'Agent', and over the mode of composition of the Agent of the embedded verb. 
lower verb in "clitic climbing" constructions. A purely syntactic alternative to the derivation of (47) would be to follow Bruening (2006) in assuming that the verb's object is a null pronoun that moves to adjoin above the VP dominated by laissé. Movement of the null pronoun leaves a trace, and abstracts over the adjoined-to structure, creating a constituent of type $<\mathrm{e}$,st $>$. This would be as in (50).

$\lambda \mathrm{e}^{\prime} \exists \mathrm{e}\left[\mathrm{let}\left(\mathrm{e}^{\prime}, \mathrm{e}\right) \wedge \mathrm{Agent}\left(\mathrm{e}^{\prime}\right.\right.$, citizens $) \wedge \operatorname{deceive}(\mathrm{e}, \mathrm{citizens}) \wedge \mathrm{Agent}(\mathrm{e}$, mayor $\left.)\right]$

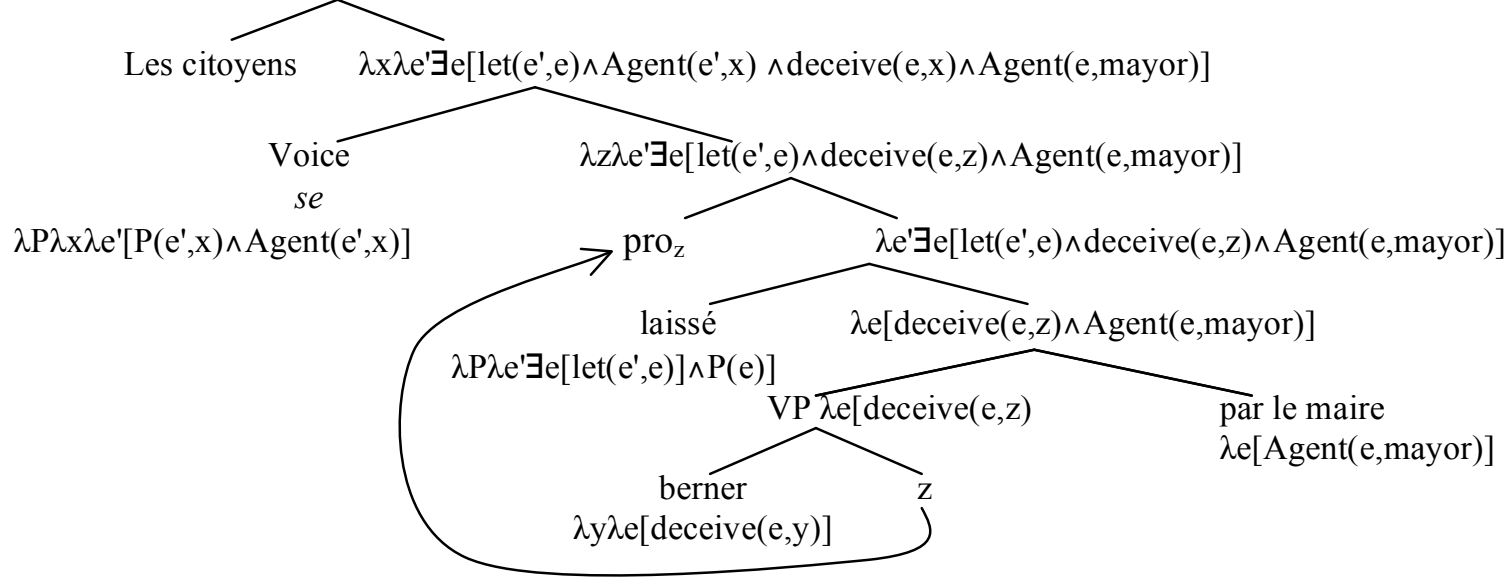

For our purposes, either approach would yield the correct results. In either case, se does not operate at the lexical level, and, crucially, it affects neither the argument structure nor the case feature of the verb to which it is cliticised.

Note that the present approach is an improvement on the Bundling operation of Reinhart and Siloni. Bundling yields a complex thematic role, easily definable when only one event is involved: [Agent-Theme](e, Max). In (47), however, the two arguments belong to distinct events: the DP in Spec,Voice is the Agent of laisser and the Theme of berner. It is unclear how Bundling could work here. 


\section{$6 \quad$ Applicatives}

The theory according to which se absorbs the case assigning feature of a verb faces a different type of problem in cases where the relevant complement is not a lexical argument of a verb. This is the case with the so-called ethical se, where se is interpreted as some type of benefactive object. Here, the lexical entry of the verb has no case feature associated with the ethical dative.

(51) a. Luc s' est bu un petit café. / s' est envoyé un petit café

Luc SEAUX drink-PP a small coffee. / SEAUX send-PP a small coffee derrière la cravate

behind the tie.

'Luc had himself a small cup of coffee'

b Alors, on se le mange, ce melon?

Well, we SE 3S-ACC eat-PRES-3S, this melon?

'Well, are we going to eat it, this melon?'

Pylkkänen (2008) proposes to derive unselected benefactive complements with the help of an applicative head. An applicative morpheme adds an unselected object to a predicate. In the case of the benefactive, the applicative morpheme is generated under a high applicative head that combines with VP by Event Identification, the special mode of composition postulated for Active Voice by Kratzer. This head denotes a relation between an event and an individual.

(52) High applicative (benefactive) : $\lambda x \lambda \mathrm{e}[\operatorname{Benefactive}(\mathrm{e}, \mathrm{x})]$ 
The benefactive complement is thus an argument of the applicative head, and not of the verb itself. If this approach to unselected complements is correct, it cannot be that se is a lexical operator on the verb. The fact that se appears when the benefactive complement is coreferential with the subject, favours an approach where se is added in the course of the syntactic derivation rather than in the lexicon.

The derivation of the first clause of (51a) is illustrated in (53). The VP is of type $<$ s,t $>$ (its object is saturated), and as such it is incapable of combining with se. The benefactive applicative head adds a dative benefactive object above the VP, and creates a predicate of the appropriate type $<\mathrm{e}, \mathrm{st}>$. When $s e$ is added at the level of the Voice head, it agrees with the dative case feature on the benefactive head, and it adds an Agent role to the Benefactive argument. When the subject $L u c$ is added in Spec,Voice, it saturates both roles.

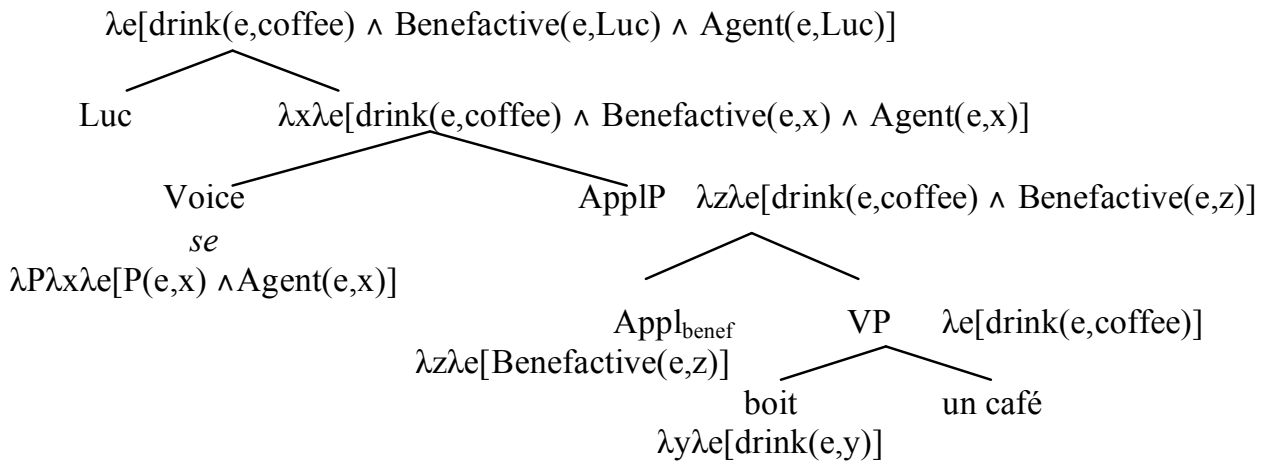

The inalienable possession construction illustrated in (54)-(55), where se is the possessor of the definite DP object, raises the same type of problem as the benefactive. Here again, the inalienable possessor is not an argument of the verb in the lexicon, and there is no reason to think that the verb is lexically associated with dative Case. 
(54) Luc se coupe les cheveux.

Luc SE cut-PRES-3S the hair.

'Luc cuts his hair.'

(55)

Luc et Eva se coiffent mutuellement les cheveux.

Luc and Eva SE comb-PRES-3P mutually the hair.

'Luc and Eva comb each other's hair.'

We might want to extend Pylkkänen's approach of low applicatives to these elements (Pylkkänen, 2008; see also Cuervo, 2003). Pylkkänen discusses two types of low applicatives, some introducing a recipient ('to the possession of $x$ '), and others a source ('from the possession of $\left.\mathrm{x}^{\prime}\right)$. Inalienable possessors denote entities that are in possession of the object, and they fit naturally into this class. For Pylkkänen, low applicatives are generated below the VP level, but above the verb's object:

(56)

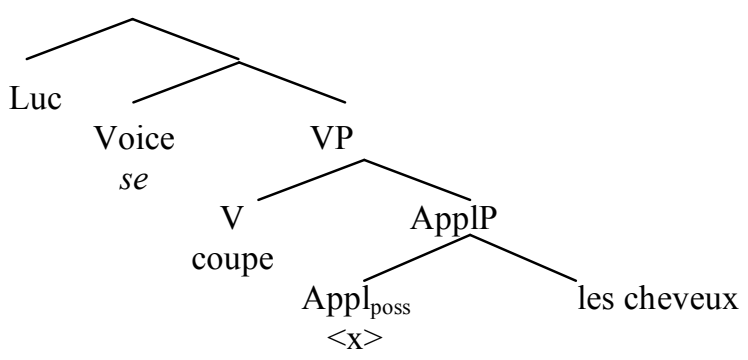

I will not go into the details of the derivation (see Pylkkänen, 2008), but simply point out that here again, the applicative head adds a dative argument without which the VP would be saturated and would not be able to combine with se. Notice that the inalienable possessive construction can be embedded under a causative head in a faire-par construction, with se on the causative verb binding the possessor of the embedded object: 
(57)

Luc se fait $\quad$ [couper $<\mathrm{x}>$ les cheveux par Figaro].

Luc SE cause-PRES-3S [cut $\quad<x>$ the hair by Figaro]

'Luc has his hair cut by Figaro.'

A look at the structure of this sentence in (58) should make it clear that, from its position under Voice, se cannot absorb in the lexicon a case assigned to the dative object of the low applicative. Consequently, if case plays a role in reflexive clauses, it cannot be the one put forward in approaches assuming that se lexically absorbs a case feature on the verb to which it cliticises.

$(58)$

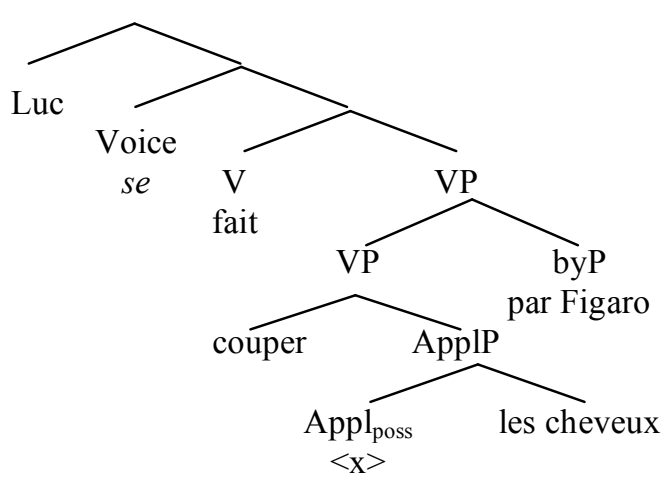

To summarise, I have shown that se does not operate on the verb in the lexicon, whether to reflexivise it or to affect its case-assigning properties. Unaccusative and case-absorption approaches to se are too local to account for the possibility of finding se on a head where the reflexivised object is an argument of a distant head. 


\section{French reflexives as "open", "near-reflexive" predicates}

In what precedes, I have assumed that, when se combines with a VP containing a variable, it assigns an Agent role to the variable, which then bundles two thematic roles, a VP internal one, and the role of Agent. In what follows, I will show that this is an oversimplification of the facts, and that the two entities, Agent and object, are potentially distinct. I therefore propose to revise the lexical entry of se proposed in (12) to the one given in (59), where $f$ denotes a function, the Near-Reflexive function, that ranges over entities distinct from $\mathrm{x}$ but related to it (what 'related' means will be discussed below) :

$$
\lambda P \lambda x \lambda y \lambda e[P(e, y) \text { and Agent }(e, x) \text { and } y=f(x)]
$$

In (59), the two arguments of the verb potentially denote distinct individuals. When a DP is introduced in Spec,Voice, two things happen: 1) the referent of this DP receives the external thematic role and 2) the referent of the object is specified as being a function of that of the subject. This formula may be reduced to a one-place predicate by replacing $y$ by $f(x)$ everywhere.

It will be concluded that French reflexive/reciprocal predicates denote a situation with two distinct participants, each with its own thematic role, as opposed a situation in which one participant has two thematic roles. Consequently, reflexive/reciprocal se does not reduce the semantic valency of the predicate. What it does is classify the predicate as reflexive by introducing (59) in the interpretation. If this is correct, the derivation of reflexive sentences is

conform to the postulates in Baauw and Delfitto (2005) and Reinhart and Siloni (2004): the computational system does not perform valency operations in syntax. The formula also does not violate Reinhart and Reuland's (1993) IDI condition (Inability to Distinguish Indistinguishables), 
claiming that the computational system cannot read as two objects the two tokens of the same variable.

The argumentation will be developed in two steps. In section 7.1, I define the notion of 'near-reflexivity' and show that French reflexives are near-reflexives, where the referent of the object is a function of that of the subject. In section 7.2, I show that French reflexives are 'open' predicates, that is, predicates with two unbound arguments.

\subsection{Step 1: French reflexives as near-reflexive}

The difference between Pure-reflexive predicates and Near-reflexive predicates has been discussed by a number of authors (Lidz, 1997, 2001:131; Reuland, 2001, 2005; see also Rooryck and Vanden Wyngaerd, 1999a). Pure-reflexive predicates are those where the two arguments of the predicate are completely identical, both in the world and in the semantic representation. Nearreflexive predicates are those where the second argument is a function taking the first argument as input and returning an entity related to that argument but distinct from it:
a. $\lambda x[P(x, x)]$
(Semantic/Pure-reflexive)
b. $\lambda x[P(x, f(x))]$
(Near-reflexive)

The Near-Reflexive function $f$ does not prohibit the antecedent and the anaphor from being the same entity in the world, but it does not require it.

The near-reflexive interpretation is observed in Tussaud contexts (Jackendoff, 1992). Imagine that Ringo Starr goes to Madame Tussaud's wax museum and sees a statue depicting himself with a beard. Because he prefers to see himself without a beard, he takes out his razor and shaves the statue. In this context we can say Ringo shaved himself. This means that in 
English the reflexive morpheme may take as antecedent a referent distinct from the subject, and that it has a near-reflexive interpretation.

The Near-Reflexive function $f$ is associated by Reuland (2005) with a condition of near identity:

(61) Condition: $\|\mathrm{f}(\mathrm{x})\|$ is sufficiently close to $\|\mathrm{x}\|$ to stand proxy for $\|\mathrm{x}\|$.

A reflexive predicate may have a near-reflexive interpretation on the condition that the referent of the object be a close copy of the referent of the subject, so that it can 'stand proxy' for it. A statue of Ringo may stand proxy for Ringo, but a book about Ringo may not, for example.

Lidz (2001) shows that reflexive morphemes differ in their ability to function as pure reflexives or as near reflexives. In Kannada, for example, when the verb is marked as reflexive in the lexicon, only the pure-reflexive reading obtains. When a morphologically complex anaphor is used instead of the reflexive morpheme, the near-reflexive interpretation is available. Thus, in (62a), Hari can only see himself, not a representation of himself such as a wax copy; both interpretations are allowed in (62b).

(62) a. Hari tann-annu nod-i-koND-a. (Lidz 2001, ex. 10a-b)

Hari self-ACC see-PP-REFL.PST-3SM

'Hari saw himself (=Hari, *wax statue).'

b. Hari tann-annu-tanne nod-id-a

Hari self-ACC-self see-PST-3SM

'Hari saw himself (=Hari or wax statue).' 
Doron (2003:58) presents a similar contrast in Hebrew, showing that middle voice creates a pure reflexive predicate, while a full pronoun (barely) allows a near-reflexive reading. In both languages, a lexical reflexive morpheme creates a reflexive predicate, while a syntactic reflexive morpheme creates a near-reflexive predicate.

Coming back to French, example (63) shows that the near-reflexive interpretation is possible in a Tussaud context, as expected if se is a syntactic head.

(63) Luc a pu s’ admirer au Musée Tussaud.

Luc AUX can SE admire at-the Museum Tussaud

'Luc was able to admire himself at the Tussaud Museum.'

Rooryck and Vanden Wyngaerd (1999a, ex. (14)) claim with the following examples that se...luimême is preferred in this type of context. For them, se...lui-même is a complex anaphor, and “only complex anaphors seem capable of occurring in a 'Doppelgänger' context”.

(64) a. Au bal masqué, Freddy et Sally pouvaient se voir *?(eux-mêmes) at-the ballmasquerade, Freddy and Sally could SE see *?(themselves) sans miroir.

without mirror

'At the masquerade ball, Freddy and Sally could see themselves without mirror.'

b. Dorian Gray se voyait *?(lui-même) dans la peinture tel qu' il aurait dû Dorian Gray SE saw *?(himself) in the painting as he should have être. been 
'Dorian Gray saw himself in the painting as he should have been.'

I personally find the versions without a full pronoun more acceptable than '*?', and an anonymous reviewer finds the versions with lui-même/eux-mêmes 'quite odd'. Clearly, se may appear in a Tussaud context without being accompanied by lui-même. What is important for us here is that, whether with or without lui-même, (63) and (64) are constructed with se; they are ungrammatical without it. Therefore, se appears in the clause when the two arguments of the reflexive predicate do not refer to exactly the same individual. Hence, the formula for the reflexive that we have used up to now must be replaced by the near-reflexive formula in (65). ${ }^{19}$

$$
\lambda \mathrm{P} \lambda \times \lambda \mathrm{e}[\mathrm{P}(\mathrm{e}, \mathrm{f}(\mathrm{x})) \text { and } \operatorname{Agent}(\mathrm{e}, \mathrm{x})]
$$

Observe that reciprocals are possible in a basic Tussaud context. In (66) Pierre admired a statue of Luc and Luc admired a statue of Pierre.

(66) $\mathrm{Au}$ Musée Tussaud, Pierre et Luc ont pu s' admirer l'un l'autre. at-the Museum Tussaud, Pierre and Luc AUX could SE admire each other $\sqrt{ }$ 'At the Tussaud Museum, Pierre and Luc could admire each other.'

${ }^{19}$ Notice that the approach sketched in (14), where se combines with the VP by Event Identification, would require postulating a special rule of composition devised exclusively for se, like the following, proposed by one of the reviewers:

(i) open-ident $(\alpha<\mathrm{e},<\mathrm{s}, \mathrm{t}>>, \beta<\mathrm{e},<\mathrm{s}, \mathrm{t}>>) \equiv \lambda \mathrm{P} \lambda \mathrm{y}_{\mathrm{e}} \lambda \mathrm{e}_{\mathrm{s}}[\alpha(\mathrm{e}, \mathrm{y})$ and $\mathrm{P}(\mathrm{e}, \mathrm{f}(\mathrm{y}))](\beta)$. 
This shows that reciprocals are also near-reflexive, that is constructions with an object potentially distinct from the subject.

\subsection{Step 2: French reflexives as 'open' predicates}

Sells et al. (1987) show that reflexive predicates vary cross-linguistically in the mapping between the lexicon, syntax and semantics. One of the dimensions of variation is the semantic difference between 'closed' predicates and 'open' predicates. Closed predicates are defined as in (67a), where a unique variable saturates two thematic roles. Open predicates imply two semantic arguments where one refers to the same entity as the other, as in (67b).
a. 'closed': $\lambda \mathrm{x}[\mathrm{R}(\mathrm{x}, \mathrm{x})]$
(1 semantic argument)
b. 'open': $\lambda x \lambda y[R(x, y) \wedge x=y]$
(2 semantic arguments)

In (67b), the interpretation of the object is not necessarily bound to that of the subject. In Sells et al.'s terms, a closed predicate is semantically intransitive (there is only one variable), while an open predicate is semantically transitive (there are two distinct variables).

Sells et al. (1987) use the test of comparative deletion to distinguish between open and closed reflexive predicates. Closed reflexive predicates allow only the 'sloppy' identity reading in this construction. According to this test, English reflexives are semantically open, while Dutch zich reflexives are semantically closed:

(68) a. John defends himself better than Peter.

b. Zij verdedigde zich beter dan Peter. she defended REFLbetter than Peter 
'She defended herself better than Peter.'

The English sentence has three readings: 1) the sloppy reading in which than Peter is interpreted as than Peter defends himself; 2) the strict reading than Peter defends him John $_{\text {; }}$ 3) the object comparison reading than he John defends Peter. In the first reading, there is binding between the subject and object of the second conjunct. In the second and third readings, there is no coreference between the subject and object of the second conjunct. The availability of the noncoreferential readings shows that the English reflexive predicate is semantically transitive, thus open, and that the reflexive pronoun functions like a pronominal. By comparison, the Dutch sentence only has the sloppy reading; this indicates that the reflexive predicate is semantically closed, and that the object is bound to the subject.

Sells et al. (1987:187) use this test to argue that the reflexive affix $d z i$ in Chichewa functions like a pronominal because it allows the strict reading and the object comparison reading (69a). Mchombo (1993:195, ex. 20) uses it to argue for the difference between the reflexive and the reciprocal morphemes in this language. The reciprocal morpheme (69b) only allows the sloppy identity reading.
Alenje á-ma-dzi-nyoz-á
kupósá asodzi
2-hunters 2SM-HAB-REFL-despise-FV
exceeding 2-fishermen
'The hunters despise themselves more than the fishermen.'
... more than the fishermen despise themselves (sloppy)
... more than the fishermen despise the hunters (strict)
... more than the hunters despise the fishermen (object comparison)
b. Alenje á-ma-nyoz-án-á kupósá asodzi 


\section{2-hunters 2SM-HAB-despise-RECIP-FV exceeding 2-fishermen}

'The hunters despise each other more than the fishermen.'

... more than the fishermen despise each other (sloppy only)

The difference correlates with the morpholexical vs morphosyntactic distinction: according to Mchombo, the reciprocal is a lexical affix, but the reflexive morpheme belongs to the syntactic component. The same test is used by Doron (2003:58) to show that the Hebrew middle voice creates closed predicates, which correlates with the fact that it does not allow the near-reflexive reading.

It should be clear that if French reflexives are near-reflexives, they must be open predicates in the sense of being semantically transitive: the two arguments of the verb are potentially distinct. However, when we apply to French the test of comparative deletion, we see that only the sloppy identity reading is possible; (70) is a reflexive, (71), a reciprocal:

(70) Lucie se défend mieux que Luc.

Lucie SE defend-PRES-3s better than Luc

a. Lucie defends herself better than Luc defends himself. (sloppy)

b. *Lucie defends Lucie better than Luc defends Lucie. (strict)

(71) Les professeurs se détestent plus que les étudiants. the professors SE detest-PRES-3P more than the students

a. Professors hate each other more than students hate each other. (sloppy)

b. *Professors hate each other more than students hate professors. (strict) 
The object comparison reading is also not available, i.e. for (70) the reading Lucie defends herself better than she defends Luc, and for (71), the reading The professors hate each other more than they hate the students. The conclusion seems to be that French reflexives/reciprocals are closed predicates, a fact predicted by $(72)(=12)$.

\section{$\lambda \mathrm{P} \lambda \times \lambda \mathrm{e}[\mathrm{P}(\mathrm{e}, \mathrm{x}) \wedge \operatorname{Agent}(\mathrm{e}, \mathrm{x})]$}

But this is not compatible with the observation that French reflexives are near-reflexives. The sloppy reading observed in comparative deletion is surprising in view of Lidz's claim that there is a correlation between that reading and the availability of the Tussaud near-reflexive reading. The French facts show that this correlation does not hold generally: in French reflexives, only the sloppy identity reading is possible in comparative deletion, but we saw that the nearreflexive reading obtains. I suggest that this is because se is not an independent anaphoric pronoun like himself, but a Voice head introducing (65) in the interpretation. We get the nearreflexive reading, but we still expect only sloppy identity to be possible, as shown in (73). The Near-Reflexive function does not range over entities distinct from and unrelated to Luc, like Lucie. $^{20}$

${ }^{20}$ Doron and Rappaport Hovav (2007) show that ECM and causative predicates allow the remnant reading illustrated below:

(i) Paul se trouvait bête et sa soeur aussi.

Paul SE find-PST stupid and his sister too

'Paul considered himself stupid, and he considered his sister stupid too.' 
(73) a. Lucie se défend mieux que Luc.

Lucie SE defend better than Luc

'Lucie defends herself better than Luc.'

b. Lucie defends herself better than Luc defends himself. (sloppy)

c. ...than Luc $\lambda x \lambda e[\operatorname{defend}(\mathrm{e}, \mathrm{f}(\mathrm{x})) \wedge \operatorname{Agent}(\mathrm{e}, \mathrm{x})]$

For the same reason, the reciprocal reading is only compatible with a sloppy reading (on reciprocals, see Bruening, 2006 for a similar argument).

Let us now come back to (33)-(34), where lui-même is in argument position and where, by spelling-out the object, it is interpreted as placing focus on the object, that is, as overtly contrasting the object with other potential objects (without intonational prominence):

a. Le ministre se copie lui-même.

the deputy SE imitate-PRES-3s himself

b. Le ministre se parle à lui-même.

the deputy SE talk-PRES-3S to himself

A sentence with contrastive focus is uttered felicitously if there are alternatives to the focussed element such that the predication might have applied to them. In contrastive focus

This means that se does not always yield a semantically reflexive predicate under ellipsis, and provides another argument for the position defended in here that French reflexives are 'open' predicates. 
sentences, the background information is obtained by replacing the focused object by a variable ranging over other potential entities (Rooth, 1992; van Heusinger, 2004, and references therein). Consider first the case of the dative in (74b). This sentence asserts (75a) against a background in which the Goal of the speaking event might be different from deputy:

\section{(75) a. Assertion : $\lambda \mathrm{e}[$ speak-to(e,deputy) $\wedge$ Agent(e,deputy)] \\ b. Background: $\lambda x \lambda e[\operatorname{speak}-$ to $(e, x) \wedge \operatorname{Agent}(e, d e p u t y)]$}

But (75) implies that French reflexive/reciprocal sentences with se are not closed predicates: the interpretation of the predicate requires us to postulate two distinct variables for the Agent and the Goal. ${ }^{21}$ The crucial point of contrastive focus is to acknowledge the possibility that the object might be a distinct individual, that is, in (75), that $\mathrm{x} \neq$ deputy. If se lexically creates a closed predicate of type $\mathrm{R}(\mathrm{x}, \mathrm{x})$ where the object is bound to the subject, the possibility of considering distinct referents for the object should be excluded. Sentence (74b) would either be uninterpretable or it would be interpreted as stating that the deputy speaks to himself against a background in which some other person speaks to himself. This is not the interpretation of that sentence.

The interpretation described in (75) follows naturally if reflexive sentences are open sentences. Assume that the lexical entry of se is (76), which combines the near-reflexive formula in (65) with the open formula in (67b). The two-place (76) reduces to the one-place (65) by replacing $y$ by $f(x): \lambda \mathrm{P} \lambda \mathrm{x} \lambda \mathrm{e}[\mathrm{P}(\mathrm{e}, \mathrm{f}(\mathrm{x}))$ and $\operatorname{Agent}(\mathrm{e}, \mathrm{x})]$. As we will see, the long formula will be

\footnotetext{
${ }^{21}$ A similar point is made in Rooryck and Vanden Wyngaerd (1999a).
} 
useful when we discuss negative sentences, as it allows for $\mathrm{y}$ to be not even representationally close to $\mathrm{x}$.

(76) $\lambda P \lambda x \lambda y \lambda e[P(e, y)$ and $\operatorname{Agent}(e, x)$ and $y=f(x)]$

In (76), the identity of the object is determined by $\mathrm{y}=\mathrm{f}(\mathrm{x})$. Placing contrastive focus on the object creates a background in which y may be different from $f(x)$, i.e. a background without this condition. This is what we see in (75b).

In (74b), it is clear that lui-même is in an argument position, because it is case-marked by $\grave{a}$. On the other hand, sentences of type (74a) are structurally and semantically ambiguous. The most natural interpretation of (74a) is one where lui-même introduces object contrast, and hence, where lui-même occupies the object position. However, lui-même may also be an actor-oriented adjunct of the type illustrated earlier in (35). Agent-oriented adjunct reflexives like lui-même overtly oppose the actor with other potential actors (Gast and Siemund, 2006). This is not the natural interpretation of (74a), but, sentences similar to it allow the agent-oriented interpretation. For example, Rooryck and Vanden Wyngaerd (1999a, ex. 26) observe that in (77a), there is no shaving going on, that is, Jean-Pierre has a beard, while in (77b), Jean-Pierre is shaved, but he is not doing the shaving.
a. Jean-Pierre ne se rase pas.
Jean-Pierre NEG SE shave-PRES-3S not
'Jean-Pierre does not shave.'
b. Jean-Pierre ne se rase pas lui-même.
Jean-Pierre NEG SE shave-PRES-3s not himself 
'Jean-Pierre does not shave himself.'

In other words, (77b) presupposes that Jean-Pierre is shaved and denies that Jean-Pierre is the agent of the shaving. This interpretation of (77b) is typical of actor-oriented intensifier SELFforms. This sentence is preferably interpreted as actor-oriented, but the object contrast reading is possible in the following context: Lieutenant Columbo looks closely at a photograph that he thought showed Jean-Pierre shaving, but he notices that the person shaved (who is only partially visible) cannot be Jean-Pierre. In that context (77b) would be felicitous, and the sentence would mean that Jean-Pierre is shaving someone, and that someone is not himself. While the preferred interpretation of (74a) is object-oriented and that of (77b) actor-oriented, (78) is ambiguous. It is equally compatible with an interpretation in which Luc was denounced (e.g. he is in prison), but not by himself, and with a context in which Luc denounced his friends, but not himself (e.g. he is free).

(78) Luc ne s' est pas dénoncé lui-même.

Luc NEG SE AUX not denounce-PP himself

'Luc did not denounce himself.'

As expected, the agent-oriented interpretation is not available when lui-même is dativemarked, as in (74b) or similar sentences, because this reading is characteristic of reflexives in an adjunct position. In (74b), the pronoun is in argument position, and its interpretation is strictly object-oriented. We conclude that the construction illustrated in (74a) is ambiguous between object contrast and subject contrast. In the object contrast reading, lui-même occupies the casemarked object position. In the subject contrast reading, lui-même is an adjunct. In both cases, the 
semantic interpretation of the sentence is of the type given in (79), where lui-même focuses an argument of the verb (subject or object) and explicitly states that it is a function of the other, against a background where both referents might be completely distinct:

(79) Assertion : $\lambda x \lambda y \lambda e[R(e, y) \wedge \operatorname{Agent}(e, x) \wedge y=f(x)]$

Background: $\lambda y \lambda x \lambda e[R(e, y) \wedge \operatorname{Agent}(e, x)]$

The distinctness of the two variables surfaces clearly under negation. The two interpretations of (77b) are given in (80):
a. $\quad \lambda \mathrm{e} \exists \mathrm{x}[\operatorname{shave}(\mathrm{e}$, Jean-Pierre $) \wedge \operatorname{Agent}(\mathrm{e}, \mathrm{x}) \wedge \neg($ Jean-Pierre $=\mathrm{f}(\mathrm{x}))]$
b. $\quad \lambda \mathrm{e} \exists \mathrm{y}[\operatorname{shave}(\mathrm{e}, \mathrm{y}) \wedge \operatorname{Agent}(\mathrm{e}, J$ Jean-Pierre $) \wedge \neg(\mathrm{y}=\mathrm{f}($ Jean-Pierre $))]$

The negation denies the near-equality between the two variables, and we end up with an interpretation where the subject is neither the same individual as the object nor related to it by a near-reflexive function. This is predicted by (76), but not by (72).

To summarise, se...lui-même sentences provides evidence that reflexive sentences are semantically open. This is particularly clear in negative sentences.

Turning to the reciprocal, it can be seen in (81) that the negative clause only has a reading parallel to that of the English translation where the whole clause is negated. The interpretation in (81c) is compatible with a situation in which the children imitate someone else, but it does not express it directly. 
(81) a. Les enfants s' imitent les uns les autres.

the children SE imitate-PRES-3P the ones the others

'The children imitate one another.'

b. Les enfants ne s' imitent pas les uns les autres.

the children NEG SE imitate-PRES-3P not the ones the others

'The children don't imitate one another.'

c. $\quad \neg \lambda \mathrm{P} \lambda \mathrm{X} \lambda \mathrm{Y} \lambda \mathrm{e}[\mathrm{P}(\mathrm{e}, \mathrm{Y}) \wedge \operatorname{Agent}(\mathrm{e}, \mathrm{X}) \wedge \mathrm{Y}=\mathrm{f}(\mathrm{X})]$

This does not mean that reciprocals are semantically closed, because they allow a near-reflexive interpretation. The difference with lui-même is that the complex pronoun les uns les autres does not introduce focus on the object. The role of l'un l'autre is to force the reciprocal reading of the reflexive, which is otherwise ambiguous between a reflexive and a reciprocal reading.

We should not leave the issue of focus without noting that se, which appears as expected in (82a), is excluded in the presence of ne...que 'only', as shown by the contrast between (82b) and (82c). This is due to the presence of the focus operator ne...que meaning only.

(82) a. Luc se dessine.

Luc SE draw-PRES-3S

'Luc draws himself.'

b. Luc ne dessine que lui-même.

Luc NEG draw-PRES-3S only himself

'Luc draws only himself.'

c. *Luc ne se dessine que lui-même.

Luc NEG SE draw-PRES-3S only himself 
The absence of se in (82b) follows if the assertion of this clause is (83), which is not reflexive (cf. van Heusinger, 2004; Geurts and van der Sandt 2004). Ne...que $X$ literally spells-out the first part of the assertion Nobody but X.

(83) Assertion: Nobody but Luc is such that Luc draws him.

To summarise, we saw that French reflexive and reciprocal clauses are open, nearreflexive constructions. This implies that the lexical entry of se is not of type $\lambda \mathrm{x}[\mathrm{P}(\mathrm{x}, \mathrm{x})]$, where the object and the subject are the same individual. In French, the two arguments of the reflexive verb are semantically distinct, and the object variable behaves in the semantics like a pronominal. It was argued that the facts follow if se contributes (76) to the interpretation. This means that when se is introduced under Voice, two things happen: first an external argument is introduced; second the referent of the object is specified as being related to the external argument by the Near-Reflexive function $f$ ranging over entities sufficiently close to the external argument to be able to stand proxy for it.

\subsection{French reflexives and metonymic readings}

When we consider French reflexives, it appears that Reuland's near-reflexive condition that $f(x)$ stand proxy for $x$ (see (61)) is too strong if we take seriously Ruwet's remark that (84a) is not the reflexive variant of (84b), which is non-existent, but rather means (84c) (Ruwet, 
1972/76: 88, note 1). Example (85) is also from Ruwet; (86) is another example of the same type. $^{22}$

(84) a. Pierre se répète sans arrêt.

Pierre SE repeat-PRES-3S without cease

'Pierre repeats himself constantly.'

b. *Pierre répète Paul sans arrêt.

Pierre repeat-PRES-3S Paul without cease

'Pierre repeats Paul constantly.'

c. Paul répète sans arrêt les mêmes idées.

Paul repeat-PRES-3S without cease the same ideas

'Paul constantly repeats the same ideas.'

(85) a. Pierre s' est exprimé avec clarté.

Pierre SE AUX express-PP with clarity

'Pierre expressed himself clearly.'

b. *Pierre a exprimé Paul avec clarté.

Pierre AUX express-PP Paul with clarity

'Pierre expressed Paul clearly.'

${ }^{22}$ Zribi-Hertz (1978)'s observation that (a) can be paraphrased by (b) may also belong here.

a. Jean se pose. (lit. : Jean SE set_down)

'Jean is setting himself (down).' (i.e., 'Jean is sitting down')

b. Jean pose son derrière. (lit. : Jean sets_down his backside)

'Jean is setting his backside (down).' (i.e., 'Jean is sitting down.') 
c. Pierre a exprimé ses idées avec clarté.

Pierre AUX express-PP his ideas with clarity

'Pierre expressed his ideas clearly.'

(86) a. Pierre s' explique.

Pierre SE explain-PRES-3S

'Pierre explains his words/his behaviour.'

b. *Pierre explique Paul

Pierre explain-PRES-3S Paul

c. Pierre explique les agissements de Paul.

Pierre explain-PRES-3S the acts of Paul

The verbs in these examples do not take a proper name as complement. While the subject is the individual Pierre, the object is Pierre's ideas or Pierre's words/acts. Because the referent of the complement is not representationally close to the subject, the near-reflexive condition as formulated does not play a role in (84)-(86).

The examples are clearly related to the notion of metonymy found in Mary is reading Brecht, where Mary is reading Brecht's writings. ${ }^{23}$ In that sentence, the proper name Brecht gives an instruction to the listener to find a referent related to the person Brecht and at the same time compatible with the verb's selectional restrictions. The interpretation is that Mary is reading something that Brecht has written. Similarly, in (84a), Pierre repeats something that Pierre has said. With the verbs in (84)-(86), however, this metonymic interpretation of the object is only possible when the verb is reflexive, as shown by the $b$ examples. This suggests that the

\footnotetext{
${ }^{23}$ I thank an anonymous reviewer for the observation and the example.
} 
metonymic reading follows from the presence of se. There is clearly a relation with nearreflexives: the two arguments of the reflexive predicates are distinct entities, and the referent of the object is determined on the basis of that of the subject, taking into account the verb's selectional restrictions. We end up with an interpretation of (84a) whereby Pierre repeats his own words.

The present approach to se provides a way to account for (84)-(86). This requires extending the notion of near-reflexivity to include entities that cannot 'stand proxy' for the subject, but that are related to it by a relation of metonymy. Take example (84), repeated in (87a). Let us assume that the verb's internal argument is typed as referring to 'words' (or perhaps 'actions'). This argument is not projected in syntax. Se adds an Agent role at the level of Voice. When the subject Pierre is introduced, it receives the external thematic role of Agent. The referent of the object is then determined by the Near-Reflexive function, $f$ (Pierre) ranging over entities compatible with the verb's selectional restriction, and at the same time related to Pierre, here, the words pronounced by Pierre.

(87) a. Pierre se répète.

Pierre SE repeats

b.

$\lambda y \lambda e\left[\right.$ repeat $\left(e, y_{\text {words }}\right) \wedge$ Agent $(e$, Pierre $) \wedge \mathrm{y}=\mathrm{f}($ Pierre $\left.)\right] \rightarrow \lambda \mathrm{e}[$ repeat(e,Pierre's words $) \wedge$ Agent(e,Pierre $\left.)\right]$

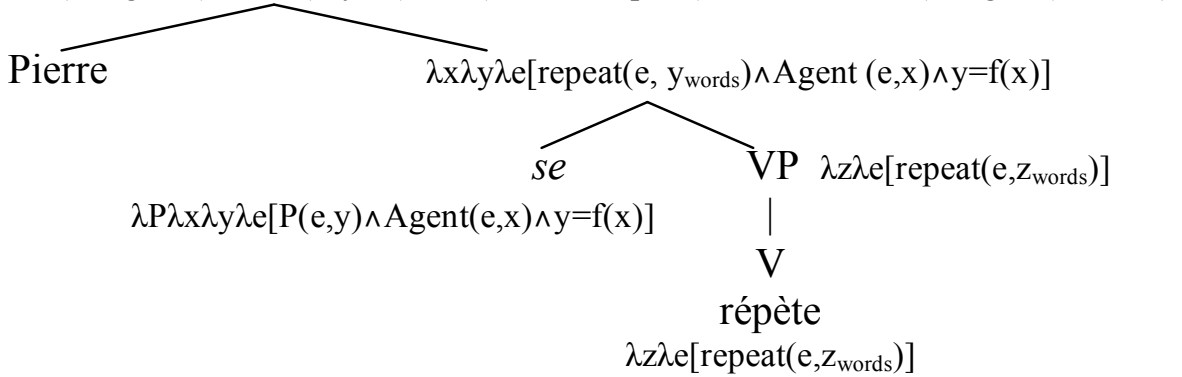


Observe that Pierre in Spec,Voice saturates the external argument, and not the internal argument (words) of the verb. This indicates that the subject of a reflexive verb is not moved to that position from the internal object position and that an unaccusative analysis is not appropriate. The fact that there is no identity here between the referents bearing the external and the internal thematic roles provides further evidence against a reduction analysis of reflexive constructions of the type presented in (2), where one of the verb's thematic roles is eliminated.

It thus appears that in French reflexive sentences the Near-Reflexive function may range over the entity denoted by $\mathrm{x}$, some entity that can stand proxy for $\mathrm{x}$, or some entity related to $\mathrm{x}$ through a metonymic relation taking into account the type of the verb's object. I find it useful to think of se as an instruction to the listener. Se tells the listener to store the referent denoted by the subject in memory, and keep the information in store until it reaches a case feature with which to agree. The referent in store is then used to find a referent for the associated variable, taking into account the meaning of the verb and the type of argument it selects. ${ }^{24}$

${ }^{24}$ A reviewer points out that what is proposed here does not seem to account for the fact that Pierre se soigne 'Pierre SE treat' has only the reading in which Pierre looks after his health, and not the reading Pierre soigne ses paroles/idées/actions 'Pierre looks after his words/ideas/ actions'. This restriction is probably due to the fact that the basic meaning of soigner is that of medical care. It could very well be that the availability and frequency of the concrete reading blocks the metonymic reading based on a figurative interpretation of the verb. Obviously more work would be required to specify exactly when the metonymic interpretation is available. The reviewer also asks about the difference between *Jean se ressemble tout le temps 'Jean always resembles himself', $\sqrt{ }$ Jean ne se ressemble plus 'Jean doesn't resemble himself anymore', $\sqrt{ }$ Plus il écrit, plus il se ressemble 'the more he writes, the more he resembles himself'. All three 
Here, the reciprocal construction behaves differently from the reflexive construction. While reciprocals appear to be possible in a basic Tussaud context, as shown in (66), the equivalents of (84) and (86) do not have a reciprocal interpretation. (88a) can only mean that Paul and Pierre repeat themselves constantly, and (88b) that they explain their own behaviours. These two sentences only have a reflexive interpretation; they do not mean that Paul repeats constantly Pierre's words and conversely, or that Paul explains the behaviour of Pierre and conversely.

$$
\begin{aligned}
& \text { a. Paul et Pierre se répètent sans arrêt. } \\
& \text { Paul and Pierre SE repeat-PRES-3P without cease } \\
& =\sqrt{ } \text { 'Paul and Pierre repeat themselves constantly.' (reflexive) } \\
& \neq * \text { 'Paul and Pierre repeat each other constantly.' (reciprocal) } \\
& \text { b. } \quad \text { Paul et Pierre se sont expliqués. } \\
& \text { Paul and Pierre SE AUX explain-PP } \\
& =\sqrt{ } \text { 'Paul and Pierre explained their own behaviour.' (reflexive) } \\
& \neq^{*} \text { 'Paul and Pierre explained each other's behaviour.' (reciprocal) }
\end{aligned}
$$

sentences are reflexive: Jean looks/does not look like himself (like what he truly is; like what he was before); the resemblance is not physical, but it is not clear that metonymy is at play here. It could be that the first sentence is rejected because it is not sufficiently informative.

${ }^{25}$ A reviewer notes that a distinct reciprocal interpretation obtains, where ' $\mathrm{J}$ explained (laid out) his point to $\mathrm{M}$ and $\mathrm{M}$ explained hers back.' This is a reciprocal interpretation based on the reflexive: J s'est expliqué (à M) and M s'est expliquée (à J), where the dative reciprocal objects are identical to the subjects. 
This follows from the fact that in order to have a reciprocal interpretation, the object must be able to function as subject of the relation described by the verb. In the representationally close context of the Tussaud Museum, it is possible to interpret the object as a "version" of Pierre and Paul; the object may "stand proxy" for the subject. In some sense, Paul admires Pierre and Pierre admires Paul, even though what they admire is a wax representation of each other. But in (88), the object is not representationally close to the subject, and it cannot serve as a subject of the reciprocal relation. I conclude that, in a reciprocal, $f(x)$ is subject to the condition proposed by Reuland in (61): it is limited to entities that can stand proxy for $\mathrm{x}$. In a reflexive, $\mathrm{f}(\mathrm{x})$ may range over a larger set and include entities related to $\mathrm{x}$ by a metonymic relation.

The crucial point of this section is that the metonymic readings exemplified show once again that reflexive/reciprocal sentences with se contain two distinct arguments, and not one argument bearing two thematic roles.

In the last two sections, I briefly address the question of the difference between se and other clitics, and that of the difference between reflexives/reciprocals and middles/anticausatives.

\section{$8 \quad$ Reflexive/reciprocal se vs other pronominal clitics}

The present approach treats se as a Voice head. This reminds us that Sportiche (1996, 1998) proposed that French pronominal object clitics head what he called clitic Voice projections. What is then the difference between se and other clitic voices?

Given the superficial similarity between Luc se lave 'Luc washes himself' and Luc le lave 'Luc washes him', the traditional grammar of French treats se as a reflexive 'pronoun', but it is now generally accepted that clauses with clitic se behave differently from clauses with a regular pronominal clitic (Kayne, 1975; Grimshaw, 1982; Wehrli, 1986). A clause with an accusative 
clitic behaves like a transitive clause, but when the clitic is reflexive, the clause behaves like an intransitive. The main arguments for this position are the following:

NP extraposition. Impersonal constructions are rejected with transitive verbs (89a), but they are allowed with intransitive and with reflexive sentences (89b)-(90) (provided their meaning is semantically appropriate for the construction):

(89) a. *Il les a dénoncés trois mille hommes ce mois-ci. there 3P-ACCAUX denounce-PP three thousand men this month-here 'Three thousand men denounced them this month.'

b. Il s' est dénoncé trois mille hommes ce mois-ci. there SE AUX denounce-PP three thousand men this month-here 'Three thousand men denounced themselves this month.'

(90) a. Il s' est offert une femme pour mener le combat.

it SE AUX offer-PP a woman to lead the fight 'A woman offered herself to lead the fight.'

b. Il s' est présenté beaucoup d' hommespour cet emploi. it SE AUX present-PP many of men for this job 'Many men presented themselves for this job.'

Causative sentences. Transitive verbs embedded under causative faire have a dative subject; reflexive and intransive verbs, an accusative subject. In (91a), the object of laver is the clitic le on the main verb faire, and its subject is the dative complement à Paul. By contrast, if the verb 
embedded under faire is reflexive, as in (91b), its subject is in the accusative, just like subject of the intransitive verb manger in (91c).

(91) a. Je le ferai laver à Paul.

I 3S-ACC make-FUT-1s wash to Paul.

'I will make Paul wash it.'

b. Je ferai se laver Paul.

I make-FUT-1S SE wash Paul

'I will make Paul wash himself.'

c. Je ferai manger Paul.

I make-FUT-1s eat Paul

'I will make Paul eat.'

This is taken by Kayne (1975) to show that reflexive clauses behave like intransitives. ${ }^{26}$

${ }^{26}$ If the reflexive clitic occurs on the main verb, as in (i), the subject of the embedded verb is neither accusative nor dative; it must be introduced by the preposition par.

(i) Il se fera laver par Paul.

He SE make-FUT-3S wash by Paul

'He will make Paul wash himi.'

According to Tasmowski-De Ryck and van Oevelen (1987:54) se faire $V$ is only possible with the faire par construction because in se faire $V$, the action is oriented towards the subject of faire, and it cannot have a second center of interest. In faire àlfaire $N P$ the subject of the embedded verb is the center of interest, the person who the subject of faire wants to affect, whereas in faire 
Subject-verb inversion. Werhli (1986:275, ex. 20) mentions that there is a contrast in the possibility of subject-verb inversion in WH constructions. It is more difficult with verbs that have an accusative clitic than with verbs that have a reflexive clitic (also Zubizarreta, 1987:163, ex. 4.51).

a. Je me demande comment s' est rasé Paul.

I 1S-DATask how SE AUX shave-PP Paul

'I wonder how Paul shaved himself.'

b. ?? Je me demande comment les a rasés Paul

I 1S-DATask how 3P-ACC AUX shave-PP Paul

'I wonder how Paul shaved them'

There is thus general agreement that se is not a regular clitic pronoun. Observe, however, that there is a difference in behaviour between clauses with se and clauses with se...lui-même with respect to the intransitivity of reflexive clauses. When lui-même is present, the clause no longer behaves like an intransitive. For example, the impersonal construction is ill-formed:

par the center of interest is the caused event, and the subject in par is instrumental in bringing about the event (Cannings and Moody, 1978; Hyman and Zimmer, 1975; Folli and Harley, 2004). It is unclear that this par is the same as that introducing the subject of a passive. 
a. Il s' est dénoncé trois mille hommes ce mois-ci.

b. *Il s' est dénoncé eux-mêmes trois mille hommes ce mois-ci. there SE AUX denounce-PP (themselves) three thousand men this month-here 'Three thousand men denounced themselves this month.'

This may be taken as a confirmation that the full pronoun occupies the object position.

Moreover, the fact that French reflexive/reciprocal clauses are open near-reflexive predicates allows us to conclude that the category bound by se functions in the semantics like a pronominal, even though reflexive clauses behave like intransitives in the absence of an anaphoric pronoun in object position. The accusative adjunct test of Sells et al. (1987) supports this conclusion. These authors show (ex. (90), p. 196) that in Serbo-Croatian a non reflexive accusative clitic can take an accusative adjunct, as can the pronominal reflexive sebe, but the reflexive clitic se cannot (in c, the auxiliary je disappears after $s e$ ):

(94) a. Petar ga je prijavio kao podstanara.

Petar-NOM him-ACC AUX registered as tenant-ACC

'Petar registered himself as tenant.'

b. Petar je sebe prijavio kao podstanara.

Petar-NOM AUX himself-ACC registered as tenant-ACC

'Petar registered himself as tenant.'

c. *Petar se prijavio kao podstanara.

Petar-NOM SE registered as tenant-ACC 
Sells et al. take the ungrammaticality of (94c) to indicate that Serbo-Croatian se does not function semantically like a pronoun, contrary to sebe and to other pronominal clitics, and that se clauses are lexically intransitive (i.e., in their terms, the verb selects only a SUBJ). If applied to French, the test shows that se allows an adjunct, just like the accusative pronominal clitic:

$\begin{array}{ccclll}\text { (95) a. } & \text { Pierre s' est } & \text { inscrit } & \text { comme } & \text { Indépendant (sur la liste électorale) } \\ \text { Pierre SE AUX } & \text { register-PP as } & \text { Independent (on the electoral list) } \\ \text { b. } & \text { Pierre l' } & \text { a } & \text { inscrit comme } & \text { Indépendant (sur la liste électorale) } \\ & \text { Pierre } 3 \text { 3S-ACC AUX } & \text { register-PP as } & \text { Independent (on the electoral list) }\end{array}$

I take this as further indication that the semantic category bound by French se is pronominal, and that reflexive clauses are semantically transitive, even though they may be syntactically intransitive.

In the analysis proposed here, how is this distinct behaviour of se to be explained? The derivation of reflexive/reciprocal clauses proposed in this paper may be compared to Delfitto's (2002) approach to non reflexive pronominal clitics. In my approach to se and in Delfitto's approach to non-reflexive clitics, a lambda operator associated with the clitic binds an internal variable, and the case feature of the clitic restricts this variable to being one associated with the appropriate case. The difference is that, while the argument of the reflexive is the clause's subject, Delfitto argues for regular clitics that the argument of the lambda is a clause external topic (see also Espinal, to appear; Zribi-Hertz 2003). The syntactically intransitive behaviour of reflexive sentences would be straightforwardly accounted for if there is no empty category in object position in the case of se, whereas clitics involve movement leaving a trace. This difference between se and regular clitics follows under the assumption that thematic roles must 
be assigned to constituents in an A position. For reflexives, the DP in Spec,Voice occupies an A position, and it can saturate at the same time the subject and the object variables. The internal thematic role is kept in the derivation until it reaches the point where the external argument is introduced, and there is no empty category in object position. With non reflexive pronominal clitics, the antecedent of the clitic is an A-bar topic. This forces the thematic role to be assigned to the object position. A slightly different idea in the same spirit is to treat the empty category bound by se as being formally similar to an NP-trace. The category bound by se is part of an Achain with the subject position. According to Chomsky (2005:27) such traces are invisible, or syntactically inert. By contrast, the category bound by the non-reflexive clitic is A-bar bound by a clause-external topic, and it must be visible. That would explain the distinct behavior of reflexive sentences compared to other object clitic constructions.

\section{Reflexive/reciprocal se vs middle/anticausative se}

In this paper, I argued that reflexive and reciprocal clauses with se are not unaccusative. In this, I concur with Alsina (1996), Reinhart and Siloni (2004) and Siloni (to appear). These authors point out, among other things, that there are dative reflexives and reciprocals, including ones with an accusative object.

(96) a. Luc s' est acheté un chapeau.

Luc SE AUX buy-PP a hat

'Luc bought himself a hat.'

b. Luc et Eva se téléphonent.

Luc and Eva SE telephone-PRES-3P

'Luc and Eva telephone each other.' 
If the above sentences result from the fact that se has absorbed a dative case feature on the verb, there must have been raising of the dative object to the subject position. But if this is possible, we would expect dative objects to surface in subject position in middles and anticausatives too. However, this is ungrammatical with anticausatives and middles as well as with the passive.

(97) a. Luc ajoute un nom à cette liste.

Luc add-PRES-3s a name to this list

'Luc added a name to this list'

b. *Cette liste s' est ajoutée (d') un nom.

(Anticausative) this list SE AUX add-PP (of) a name

'This list increased by one name.' (/'got a name added to it')

$\begin{array}{lll}\text { c. *Unetelle liste s' ajoute (facilement) de noms. (Middle) } & \end{array}$

a such list SE add-PRES-3S (easily) of names

'It is easy to add names to such a list.'

d. *Cette liste a été ajoutée (d') un nom. (Passive) this list AUX $_{\text {TNS }}$ AUX $X_{\text {PASS }}$ add-PP (of) a name

'This list has been added a name to it.'

As long as no principled explanation is given for the grammaticality of (96) in the face of the ungrammaticality of (97b-d), an unaccusative approach to reflexive/reciprocal clauses remains an unsubstantiated assumption. It would not do to say that reflexives involving a object associated with accusative case in the transitive clause are unaccusative, but not those involving 
an object associated with dative case. Under this position, the unifying factor underlying all se clauses - the main argument in favour of an unaccusative account of reflexives - disappears, and the unaccusative account reduces to a purely stipulative distinction among reflexives/reciprocals, with no independent evidence of a difference in kind between accusative and dative reflexives.

Reinhart and Siloni (2004:172, ex 24b) also offer (98) as an argument against an unaccusative approach to reflexive se. En cliticisation of the postverbal subject in an impersonal construction is possible with a medio-passive interpretation, but not with a reflexive interpretation. If en cliticisation is taken as a diagnostic that the corresponding argument is an internal argument, (98) indicates that the subject of a reflexive is not an internal argument. ${ }^{27}$

(98) Il s' en est lavé beaucoup $<$ en $>$ dans ces douches publiques there SE of-them AUX wash-PP many in these showers public récemment.

recently

'Many of them were washed in these public showers recently.' (OK passive)

*'Many of them washed themselves in these public showers recently.' (*reflexive)

${ }^{27}$ A reviewer points out that en referring to a post-verbal subject is possible with an unergative verb under proper discourse conditions. This is correct, but much less natural than with unaccusatives (cf. Labelle, 1992); it seems to require conditions forcing the projection of the argument in object position. In the case of (98), I share Reinhart and Siloni's judgement that the reflexive interpretation is impossible, while the medio-passive interpretation is natural. En would however be possible in (90). 
If reflexives and reciprocals are unergative, the unifying factor between these clauses and middles and anticausatives needs to be reconsidered. It is not my purpose here to propose a unifying account of these constructions, but I would like to suggest how the current approach of reflexive/reciprocal se can be made compatible with the existence of a middle/anticausative se.

Recall from section 2 that, in Doron's analysis of the Hebrew middle, the middle head prevents the licensing of the Active Voice head and, moreover, it may introduce an Agent. Adapting this approach to French suggests the hypothesis that there are two 'flavours' of se, one introducing an Agent and one that does not. If se introduces an Agent, the corresponding argument is merged in the specifier of Voice, and we have a reflexive or reciprocal, like the sentences we discussed in this paper. If no Agent is introduced, se is pleonastic: it does not add to what the VP contains, but it allows the internal argument to surface in subject position. The derivation then proceeds as in (99b).

$$
\begin{aligned}
& \text { a. le vase se brise } \\
& \text { the vase SE breaks }
\end{aligned}
$$

b. $\lambda \mathrm{e}[\operatorname{break}(\mathrm{e}$, the_vase $)]$

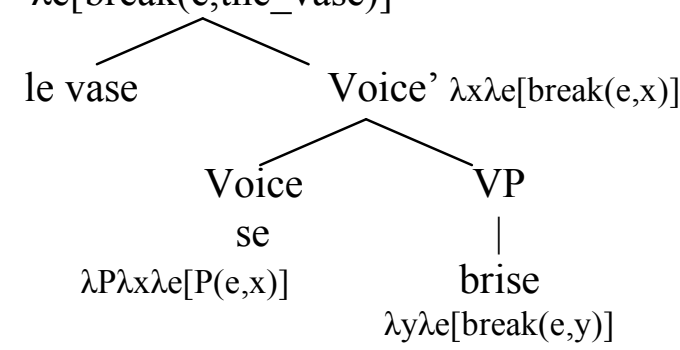


This means that there are two distinct se morphemes, one with a lexical entry containing the subpart $\lambda \mathrm{x} \lambda \mathrm{e}[\operatorname{Agent}(\mathrm{e}, \mathrm{x})]$, and the other one without it. ${ }^{28}{ }^{29}$ The two se's would share the property

${ }^{28}$ We may reinterpret this optional assignment of an Agent role by se in structural terms if we adopt the neo-constructionist view that thematic roles are not assigned by heads but are read off the structure (e.g. Borer, 2005). If Spec,Voice is projected and occupied by a DP, this DP is interpreted as the Agent, and the reading is reflexive/reciprocal. The option of not projecting Spec,Voice is freely available, in which case the derivation is unaccusative, and the reading is either middle or anticausative.

We might also develop an approach in which the difference between the two flavours of se stems from the nature of the head dominating se. Kratzer distinguishes two different Voice heads: Active Voice and Non Active Voice. Assume that these are two different functional heads. It could be that if se is generated under Active Voice, it introduces an Agent, and the reflexive/reciprocal reading results; if it is generated under Non-Active Voice, the unaccusative derivation results. As can be seen, there is a variety of options compatible with the hypothesis that $s e$ is a Voice head that may account for middles and anticausatives. I leave for future research the choice between these various alternatives.

29 An anonymous reviewer asks how considering se as introducing an external argument in reflexives accounts for examples like the following:

(i) Jean s'est blessé à l'espagnolette. 'Jean hurt himself on the window catch.'

(ii) Jean s'est irrité du comportement de Sophie. 'Jean got irritated at Sophie's behaviour.' In (i), Jean is typically interpreted as an unintentional Agent, as shown by the fact that an adjunct like par mégarde 'inadvertently' can be added, this type of adjunct telling us something about the intention of the subject. The intentional interpretation, while pragmatically dispreferred, is not 
of combining with an open VP, of type $<\mathrm{e},<\mathrm{s}, \mathrm{t}>>$, to yield a constituent of the same type. This selectional property of se would be the property shared by the two se's and distinguishing se from Active Voice, which combines with a saturated VP, of type $<\mathrm{s}, \mathrm{t}>$.

This is obviously not the end of the story. For example, the fact that the subject of a middle or anticausative construction cannot correspond to the dative object of the transitive counterpart, requires an explanation. The restriction appears to be universal, extending also to German (Steinbach 1998, 2004). Maling (2001) argues that it is underlyingly thematic: Goal

impossible: Jean s'est blessé (intentionnellement) à l'espagnolette. The phenomenon of reduced intentionality is a problem orthogonal to the present discussion (on the fuzziness of the thematic role Agent, see Dowty 1991). Thus, in (i), I believe se introduces the external argument, and the sentence is accounted for by (76).

Example (ii) must be contrasted with (iii):

(iii) Le comportement de Sophie a irrité Jean. 'The behaviour of Sophie irritated Jean.' Sentence (iii) is an active sentence without reflexive morpheme. A comparison of (ii) and (iii) shows that $s e$ in (ii) is anticausative: the internal argument Jean of (iii) surfaces in subject position in (ii), and the subject of (iii) is realised as an adjunct in (ii). Also, the preposition de/du introducing the adjunct is the one surfacing in some adjectival and verbal passives (where it alternates with par):

(iv) Jean est irrité du comportement de Sophie. 'Jean is irritated by Sophie's behaviour.' (adjectival passive)

(v) Jean est aimé de Sophie. 'Jean is loved by Sophie.' (verbal passive)

Hence it appears that (ii) is an anticausative construction. Thus, (i) and (ii) illustrate the two distinct 'flavours' of se discussed in this section. 
arguments do not undergo Middle Formation because they are "the wrong kind of internal argument" (p. 439); they are not 'affected patients' or 'themes' or whatever proves to be the best characterisation of the thematic role necessary to become the subject of a middle. The question is complex, and it requires an independent study.

I will not say anything more on this topic here, leaving for further research the question of the relation between reflexive/reciprocal se and middle/anticausative se. I want to stress however, that, under the present perspective, middle/anticausative se must be a Voice head because it prevents the projection of the external argument in syntax, and this is the role of Kratzer's Voice. From that point of view, treating reflexive/reciprocal se as a realisation of Voice is a step towards a unification with middle/anticausative $s e$.

\section{Conclusion}

In this paper, I examined the contribution of se in reflexive and reciprocal clauses, focusing on its semantic contribution. I provided evidence showing that se is not a lexical operator reducing the valency of a verb, that it does not absorb or reduce the case feature of the verb on which it appears, and that reflexive and reciprocal predicates are not unaccusative. The function of se is not simply to reflexivise a predicate because it obligatorily co-occurs with verbs containing a lexical reflexiviser like auto- or entre- and with predicates containing a reflexive pronoun like lui-même or l'un l'autre, where the use of se would be redundant. Se does not reduce the case feature of the verb on which it occurs because it is compatible with a case-marked pronoun in the reflexivised object position and because in causatives and applicatives the case of the reflexivised object is not a feature of the verb on which se surfaces. Reflexive and reciprocal se clauses are not unaccusative because the object position may be filled by a case-marked pronoun, and because in metonymic near-reflexive clauses the constituent surfacing in subject 
position spells out the external argument rather than the internal argument. Finally, se does not reduce the valency of the predicate, because reflexive and reciprocal clauses are open, nearreflexive predicates, with two distinct arguments.

I argued that the facts find a principled explanation if reflexive/reciprocal se is a Voice head whose role is to classify the predicate as reflexive by (1) assigning the external thematic role to the subject in its specifier, and (2) stating that the referent of the object is a function of that of the subject. As a consequence, French reflexive and reciprocal predicates are semantically transitive. The proposed analysis explains a number of apparent contradictions in the data: reflexive clauses behave as though they are intransitive, but a full pronoun may occupy the position of the reflexivised object; se appears to reflexivise a predicate, but it is obligatory with predicates that are already lexically or syntactically reflexive or reciprocal; clauses with se appear closed under the test of comparative deletion, but the facts regarding lui-même and the distinctiness of the subject and object referents lead us to conclude that they are open. The present proposal brings together the whole set of facts and provides a simple and coherent framework to account for them.

I do not claim that $I$ arrived at the definitive solution to the description of reflexive/reciprocal se. The lexical entry proposed for se is, at this point, purely descriptive. It could be that some of the properties of reflexives and reciprocals discussed here find a principled explanation, and may be eliminated from the lexical entry that I proposed. The present analysis of reflexive/reciprocal se also raises the question of the relation between reflexive/reciprocal se and middle/anticausative se. What I proposed suggests that there are two distinct se's. There may be a way to unify these two variants. Despite these remaining issues, I think that the present research has advanced our understanding of French reflexives and reciprocals and shown that current 
approaches based on argument reduction or case absorption are incapable of accounting for the facts discussed.

\section{Acknowledgements}

I gratefully thank Henriette de Swart, Edit Doron, Anna-Maria di Sciullo, the audience at the Universitat Autónoma de Barcelona, as well as three anonymous reviewers for their comments on previous versions of this paper. All remaining errors are mine.

\section{References}

Alboiu, Gabriela, Michael Barrie and Chiara Frigeni. 2004. SE and the Unaccusative-Unergative Paradox. In Martine Coene, Gretel de Cuyper, and Yves D'Hulst (eds.), Antwerp Papers in Linguistics 107: 109-139.

Alsina, Alex. 1996. The Role of Argument Structure in Grammar: Evidence from Romance. Stanford. California: CSLI Publications.

Baauw, Sergio and Denis Delfitto. 2005. New views on reflexivity : Delay effects in Romance. Probus 17: 145-184.

Borer, Hagit. 2005. Structuring sense. Oxford: Oxford University Press.

Bruening, Benjamin. 2006. The Morphosyntax and Semantics of Verbal Reciprocals. Ms. University of Delaware. [available at: http://www.ling.udel.edu/bruening/home/home.html] Burzio, Luigi. 1986. Italian syntax: A Government-Binding approach. Dordrecht: Reidel.

Cannings, Peter and Marvin Moody. 1978. 'A semantic approach to causation in French' Lingvisticae Investigationes II, 331-62. 
Chierchia, Gennaro. 2004[1989]. A semantics for unaccusatives and its syntactic consequences. In Artemis Alexiadou, Elena Anagnostopoulou and Martin Everaert (eds.), 2004, The unaccusativity Puzzle, 22-59. Oxford : Oxford University Press. (This is the published version of a paper written in 1989 and widely cited as a manuscript).

Chomsky, Noam. 2005. On Phases. Unpublished ms.: MIT. [Available on-line at: http://www.phon.ucl.ac.uk/home/hans/mrg/chomsky_onphases_1204.pdf]

Chung, Sandra and William M. Ladusaw. 2003. Restriction and saturation. Cambridge: MIT Press.

Cuervo, María Cristina. 2003. Datives at large. PhD. Thesis, MIT.

Dalrymple, Mary, Makoto Kanazawa, Yookyung Kim, Sam Mchombo, Stanley Peters. 1998. Reciprocal expressions and the concept of reciprocity. Linguistics and Philosophy 21 : 159210.

Delfitto, Denis. 2002. On the semantics of pronominal clitics and some of its consequences. Catalan Journal of Linguistics 1: 41-69.

Déchaine, Rose-Marie and Marina Wiltschko. 2004. Deconstructing reciprocals. Western Conference on Linguistics, University of Southern California.

Dobrovie-Sorin, Carmen. 1998. Impersonal se constructions in Romance and the passivization of unergatives. Linguistic Inquiry 29(3): 399-437.

Doron, Edit. 2003. Agency and voice : the semantics of the Semitic templates. Natural Language Semantics 11: 1-67.

Doron, Edit and Malka Rappapport Hovav. 2007. Towards a Uniform Theory of Valencechanging Operations. IATL 30, 2007.

Dowty, David. 1991. Thematic Proto-Roles and Argument Selection. Language 67(3), 547-619. 
Embick, David. 1997. Voice Systems and the Syntax/Morphology Interface. In Heidi Harley (ed.) The Proceedings of the Penn/MIT Workshop on Aspect, Argument Structure, and Events, May 1997, MIT Working Papers in Linguistics. Boston: MIT.

Embick, David. 2004. Unaccusative syntax and verbal alternations. In Artemis Alexiadou, Elena Anagnostopoulou and Martin Everaert (eds.) The unaccusativity Puzzle, 137-158. Oxford : Oxford University Press.

Espinal, Maria Teresa. To appear. Clitic incorporation and abstract semantic objects in idiomatic constructions. Linguistics.

Fiengo, Robert and Howard Lasnik. 1973. The logical structure of reciprocal sentences in English. Foundations of language 9, 447-468.

Folli, Raffaella and Heidi Harley. 2004. On obligatory obligation: the composition of Italian causatives. In Ana Castro, Marcelo Ferreira, Valentine Hacquard and Andrés Pablo Salanova (eds.) Romance, Op. 47: Collected Papers on Romance Syntax. MIT Working Papers in Linguistics 47: 87-113.

Gast, Volker and Pieter Siemund. 2006. Rethinking the relationship between SELF-intensifiers and reflexives. Linguistics 44 (2): 343-381.

Geurt, Bart and Rob van der Sandt. 2004. Interpreting focus. Theoretical Linguistics 30: 1-44.

Grevisse, Maurice and André Goose. 2007. Le bon usage. Bruxelles: De Boeck.

Grimshaw, Jane. 1982. On the Lexical Representation of Romance Reflexive Clitics. In Joan Bresnan (ed.) The Mental Representation of Grammatical Relations, 87-148. Cambridge: MIT Press.

Grimshaw, Jane. 1990. Argument Structure. Cambridge: MIT Press. 
Guasti, Maria Teresa. 1996. Semantic restrictions in Romance causatives and the incorporation approach. Linguistic Inquiry 27(2): 294-313.

van Heusinger, Klaus 2004. Focus Particles, Sentence Meaning, and Discourse Structure. In Werner Abraham and Alice ter Meulen (eds.). The Compositon of Meaning. From Lexeme to Discourse, 167-193. Amsterdam: John Benjamins.

Higginbotham, James. 1985. On semantics. Linguistic Inquiry 16 : 547-93.

Hyman, Larry M. and Karl Zimmer. 1975. Embedded topic in French. In Charles N. Li (ed.), Subject and Topic, Academic Press, New York, pp. 191-211.

Jackendoff, Ray. 1992. Mme Tussaud meets the binding theory. Natural Language and Linguistic Theory 10: $1-31$.

Kayne, Richard. 1975. French syntax : the transformational cycle. Cambridge, Mass. : MIT Press.

Kayne, Richard. 1989. Facets of Romance Past Participle Agreement. In Paola Benincá (ed.), Dialect Variation on the Theory of Grammar, 85-104. Dordrecht: Foris.

Kratzer, Angelika. 1996. Severing the external argument from its verb. In Johan Rooryck and Laurie Zaring (eds.) Phrase structure and the lexicon, 109 - 137. Dordrecht: Kluwer.

Labelle, Marie. 1992. Change of state and valency. Journal of Linguistics 28: 375-414.

Lidz, Jeffrey. 1997. When is a reflexive not a reflexive? Near-reflexivity and Condition R. NELS $27,251-261$.

Lidz, Jeffrey. 2001. Condition R. Linguistic Inquiry 32(1):123-140.

Maling, Joan. 2001. Dative: The heterogeneity of the mapping among morphological case, grammatical functions, and thematic roles. Lingua 111, 419-464.

Marantz, Alec P. 1984. On the nature of grammatical relations. Cambridge, Mass.: MIT Press. 
Mchombo, Sam A. 1993. On the binding of the reflexive and the reciprocal in Chichewa. In Sam A. Mchombo (ed.) Theoretical aspects of Bantu Grammar. Stanford : CLSI Publications.

McGinnis, Martha. 1997. Reflexive External Arguments and Lethal Ambiguity. In Emily Curtis, James Lyle, and Gabriel Webster (eds.) Proceedings of WCCFL 16, 303-317. Stanford: CSLI Publications.

McGinnis, Martha.1999. Reflexive clitics and the specifiers of vP. Papers from the Penn/MIT Workshop on the Lexicon, 137-161. MIT Working Papers in Linguistics 35.

Miller, Philip H. 1992. Clitics and Constituents in Phrase Structure Grammar. New York: Garland. Downloadable at the following address: http://www.univ-lille3.fr/silex/miller/ these_fr.html.

Milner, Jean-Claude. 1984. Syntaxe et sémantique du constituant réciproque l'un...l'autre. Recherches sur l'anaphore. Collection ERA642. Département de recherches linguistiques, Laboratoire de Linguistique Formelle, Université Paris 7.

Pesetsky, David. 1995. Zero Syntax. Experiencers and Cascades. Cambridge, MA : MIT Press.

Pylkkänen, Liina. 2008. Introducing arguments, MIT Press, Cambridge, MA.

Quine, Willard Van Orman. 1961. Variables Explained Away. Proceedings of the American Philosophical Society 104(3), 343-347. Reprinted in Willard Van Orman Quine, Selected Logic Papers, Harvard University Press, 1966.

Reinhart, Tanya. 1996. Syntactic effects of lexical operations: Reflexives and unaccusatives. OTS Working Papers in Linguistics. Utrecht: Utrecht University, OTS.

Reinhart, Tanya and Eric Reuland.1993. Reflexivity. Linguistic Inquiry 24: 657-720. 
Reinhart, Tanya and Tal Siloni. 2004. Against an unaccusative analysis of reflexives. In Artemis Alexiadou, Elena Anagnostopoulou and Martin Everaert (eds.) The unaccusativity Puzzle, 159-180. Oxford University Press.

Reinhart, Tanya and Tal Siloni. 2005. The lexicon-syntax parameter: Reflexivization and other arity operations. Linguistic Inquiry 36(3): 389-436.

Reuland, Eric. 2001. Primitives of Binding. Linguistic Inquiry 32(2): 439-492.

Reuland, Eric. 2005. Binding Conditions: How are they Derived? In Stefan Müller (Ed.) Proceedings of the HPSG05 Conference, Department of Informatics, University of Lisbon 2005, Stanford: CSLI Publications. (http://csli-publications.stanford.edu/)

Rooryck, Johan and Guido Vanden Wyngaerd. 1999a. Simplex and complex reflexives in French and Dutch. In Martine Coene, Walter De Mulder, Patrick Dendale \& Yves D'Hulst (eds) Traiani Augusti Vestigia Pressa Sequamur. Studia Lingvistica In Honorem Lilianae Tasmowski, 617-639. Padova: Unipress.

Rooryck, Johan and Guido Vanden Wyngaerd. 1999b. Puzzles of identity: Binding at the interface. In Proceedings of NELS 29. GLSA, University of Massachusetts, Amherst.

Rooth, Mats. 1992. A theory of focus interpretation. Natural Language Semantics 1:75-116.

Ruwet, Nicolas. 1972/1976. Les constructions pronominales neutres et moyennes du français. In Théorie syntaxique et syntaxe du français, 87-125. Paris : Éditions du Seuil. (English translation 1976: 'Neutral and middle pronominal constructions', in Problems in French syntax : transformational-generative studies, Longman, London.)

Sells, Peter, Annie Zaenen and Draga Zec. 1987. Reflexivization variation: Relations between syntax, semantics and lexical structure. In Masayo Iida, Stephen Wechsler, and Draga Zec (eds.) Working papers in grammatical theory and discourse structure, 169-238. Stanford: CSLI Publications. 
Siloni, Tal. To appear. The Syntax of Reciprocal Verbs: An Overview . In Ekkehard König and Volker Gast (eds.) Reciprocals and Reflexives: Cross-linguistic and theoretical explorations. Trends in Linguistics, Mouton de Gruyter.

Sportiche, Dominique. 1988. A theory of floating quantifiers and its corollaries for constituent structure. Linguistic Inquiry 19, 425-449.

Sportiche, Dominique. 1996. Clitic constructions. In Johan Rooryck and Laurie Zaring (eds.) Phrase structure and the lexicon, 213-276. Dordrecht: Kluwer.

Sportiche, Dominique. 1998. Partitions and atoms of clause structure. London and New York: Routledge.

Steinbach, Markus. 1998. Middles in German. The syntax and semantics of transitive reflexive sentences. PhD Dissertation, Humboldt University at Berlin.

Steinbach, Markus. 2004. Unaccusatives and anticausatives in German. In Artemis Alexiadou, Elena Anagnostopoulou and Martin Everaert (eds.) The unaccusativity Puzzle. Oxford University Press, 181-206.

Tasmowski-De Ryck, Liliane and Hildegard van Oevelen. 1987. Le causatif pronominal, Revue romane $22(1), 40-58$.

Wehrli, Eric. 1986. On Some Properties of French Clitic se. In Hagit Borer (ed.) The Syntax of Pronominal Clitics, 263-283. New York: Academic Press.

Zribi-Hertz, Anne. 1978. Économisons-nous : À propos d'une classe de formes réflexives métonymiques en français. Langue française 39 : 104-128.

Zribi-Hertz, Anne. 1990. Lui-même argument et le concept de "pronom A ". Langages 97 : 100127. 
Zribi-Hertz, Anne. 1995. Emphatic or reflexive ? On the endophoric character of French luimême and similar complex pronouns. Journal of linguistics 31, 333-374.

Zribi-Hertz, Anne 2003. Réflexivité et disjonction référentielle en français et en anglais. In Philip Miller and Anne Zribi-Hertz (eds.) Essais sur la grammaire comparée du français et de l'anglais, 189-227. Saint-Denis, France: Presses Universitaires de Vincennes.

Zubizarreta, Maria-Luisa. 1987. Levels of representation in the lexicon and in the syntax. Foris, Dordrecht.

Received 9 May 2006

Revised 14 May 2008

Département de linguistique

Université du Québec à Montréal

C.P. 8888 , succ. Centre-Ville

Montréal, QC,

Canada, H3C 3P8

e-mail: labelle.marie@uqam.ca

KEYWORDS:

French, reflexive, reciprocal, clitic, near-reflexive, se, Voice. 